\title{
Optimal Taxation when People Do Not Maximize Well-Being
}

Max Planck Institute for Tax Law and Public Finance

Working Paper 2015 - 07

June 2015

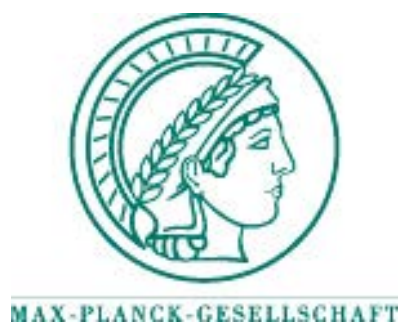

Max Planck Institute for

Tax Law and Public Finance

Department of Business and Tax Law

Department of Public Economics

http:/ / www.tax.mpg.de 
Working papers of the Max Planck Institute for Tax Law and Public Finance Research Paper Series serve to disseminate the research results of work in progress prior to publication to encourage the exchange of ideas and academic debate. Inclusion of a paper in the Research Paper Series does not constitute publication and should not limit publication in any other venue. The preprints published by the Max Planck Institute for Tax Law and Public Finance represent the views of the respective author(s) and not of the Institute as a whole. Copyright remains with the author(s).

Max Planck Institute for Tax Law and Public Finance

Marstallplatz 1

D-80539 Munich

Tel: $\quad+498924246-0$

Fax: $\quad+498924246-501$

E-mail: ssrn@tax.mpg.de

http://www.tax.mpg.de 


\title{
Optimal taxation when people do not maximize well-being
}

\author{
Aart Gerritsen*
}

June 2015

I derive the optimal nonlinear income tax when individuals do not necessarily maximize their own well-being. This generates a corrective argument for taxation: optimal marginal taxes are higher (lower) if individuals work too much (too little) from a well-being point of view. I allow for multidimensional heterogeneity and derive the optimal tax schedule in terms of measurable sufficient statistics. One of these statistics measures the degree to which individuals fail to optimize their labor supply. I empirically estimate this by using British life satisfaction data as a measure of well-being. I find that low-income workers tend to work 'too little' and high-income workers 'too much,' providing a motive for lower marginal tax rates at the bottom and higher marginal tax rates at the top of the income distribution.

JEL: H21, I31, D63

Keywords: Optimal taxation, corrective taxation, subjective well-being

\footnotetext{
* Max Planck Institute for Tax Law and Public Finance, Department of Public Economics, Marstallplatz 1, 80539 Munich, Germany. Tel.: +49-89-24246-5256; Fax: +49-8924246-5299; E-mail: aart.gerritsen@tax.mpg.de; Internet: https://sites.google.com/site/ aartgerritsen/. I thank Leon Bettendorf, Robin Boadway, Pierre Boyer, Raj Chetty, Benoit Crutzen, Robert Dur, Bas Jacobs, Sebastian Kessing, Wojciech Kopczuk, Steeve Mongrain, Matthew Rablen, Jacques Siegers, Maarten Vendrik, Hendrik Vrijburg, Floris Zoutman, and participants of numerous seminars and conferences for helpful comments and discussions. Financial support from The Netherlands Organization for Scientific Research (NWO Vidi Grant No. 452-07-013) is gratefully acknowledged.
} 
'Those who know anything about the matter are aware that every writer, from Epicurus to Bentham, who maintained the theory of utility, meant by it ... pleasure itself, together with exemption from pain.' John Stuart Mill in $\operatorname{Mill}(1863, p .8)$

'In the standard approach, the terms "utility maximization" and "choice" are synonymous.' Faruk Gul and Wolfgang Pesendorfer in Gul and Pesendorfer (2008, p.7)

Historically, the concept of 'utility' has been defined in at least two different ways. The classical definition, which follows from the first quotation, is intimately related to the well-being of its subject. Utility is seen as the ultimate 'good' and, therefore, the natural aim of consequentialist public policy. The second definition, which follows from the second quotation, is dominant in the field of economics and directly related to individual behavior. Utility is defined as a rationalization of behavior - i.e., that of which the maximization leads to observed behavior. In most of the literature on public economics and optimal taxation it is implicitly assumed that the two definition perfectly overlap. That is, individual behavior follows from utility maximization, and this same measure of utility perfectly corresponds with well-being - the aim of optimal policy.

There is, however, no necessary connection between the two definitions of utility: it might very well be that individuals consistently make choices that nevertheless do not maximize their own well-being. Indeed, increasingly many studies that attempt to measure well-being directly reject the claim that voluntary choice is always and everywhere conducive to well-being. This rejection is based on a variety of insights from the fruitful interactions between economics and neuroscience (Camerer, Loewenstein, and Prelec, 2005), psychology (Rabin, 1998; Kahneman and Thaler, 2006), and happiness research (Clark, Frijters, and Shields, 2008), as well as on straightforward introspection. Moreover, the divergence between choice-based utility and well-being is increasingly stressed by scholars of economic methodology (Hausman, 2011). ${ }^{1}$

The aim of this paper is to reassess traditional results of optimal income taxation by relaxing the assumption that individuals necessarily maximize their own well-being. I do retain the assumption that government ought to care about people's well-being. Individuals might fail to maximize well-being for a variety of reasons: because they have mistaken beliefs about what causes well-being (e.g., Loewenstein, O'Donoghue, and Rabin, 2003) or about the exact shape of their budget curve (e.g., Chetty, Looney, and Kroft, 2009; Liebman and Zeckhauser, 2004), or simply because behavior has genetic or neurological roots which need not be perfectly aligned with well-being maximization (e.g., Sanfey et al., 2003). Rather than explicitly specifying the exact mechanism that underlies

\footnotetext{
${ }^{1}$ The distinction between choice-based utility and well-being is sometimes cast in terms of 'decision utility' versus 'experienced utility,' cf. Kahneman, Wakker, and Sarin (1997).
} 
suboptimal behavior, I apply a sufficient-statistics approach to optimal nonlinear income taxation (Chetty, 2009). This allows me to remain agnostic about the specific behavioral model, while writing and interpreting the optimal tax schedule in terms of four sufficient statistics.

These sufficient statistics include behavioral elasticities, the density of the income distribution, social welfare weights, and individuals' net marginal well-being of reducing labor earnings. While the first three statistics are standard ingredients of optimal tax formulae (e.g., Saez, 2001; Piketty and Saez, 2013; Jacquet and Lehmann, 2015), the last sufficient statistic is novel and measures the degree to which an individual works "too much' from a well-being point of view. If a person's net marginal well-being of reducing labor earnings is strictly positive, he can increase his well-being by working less. This means that he works 'too much.' Conversely, if his net marginal well-being of reducing labor earnings is negative, he works 'too little.' I show that the optimal marginal income tax is increasing in the degree to which people work too much. Intuitively, higher marginal tax rates tend to reduce labor supply, which leads to well-being gains if individuals work too much and to well-being losses if they work too little. This yields a corrective argument for distortive income taxation: workers who work too much should be encouraged with higher marginal taxes to work less; workers who work too little should be encouraged with lower marginal taxes to work more. ${ }^{2}$

In deriving optimal income taxes, I allow individuals to be heterogeneous in multiple dimensions. As usual, I assume that labor income differs across individuals. On top of that, I allow both the degree to which an individual works too much and the behavioral elasticities to differ across individuals - even across individuals that earn the same labor income. This generates a number of interesting interactions between the degree to which people work too much, the behavioral elasticities, and social preferences. In the extreme case of Rawlsian social preferences, the corrective argument for taxation vanishes because government does not care about anyone's well-being except that of the worst-off. If, conditional on income, a non-Rawlsian government attaches a larger welfare weight to 'hard-working' people that work too much, than to 'lazy' people that work too little, the corrective argument of taxation is more important for the 'hard-working' than for the 'lazy', leading to higher corrective marginal taxes. Finally, if people who make suboptimal decisions are less responsive to relative prices and thus have lower elasticities, the corrective argument for taxation is weaker as taxes are less effective in influencing the behavior of those in need of correction.

\footnotetext{
${ }^{2}$ An earlier version of the paper, available on request and online on my home page, also derives optimal commodity taxes, participation taxes, and eduction subsidies. In all cases the same logic applies. If individuals consume too much of a particular commodity, positive corrective commodity taxes are called for - even under the Atkinson and Stiglitz (1976) conditions for uniform commodity taxation. Similarly, if an individual underestimates the value of labor participation or education, positive corrective participation or education subsidies are called for.
} 
In the second part of the paper, I attempt to empirically determine the degree to which people work too much or too little. That is, I empirically measure the fourth sufficient statistic which determines the importance of the corrective argument for distortive taxation. Obviously, I cannot rely on revealed preferences to identify whether people behave suboptimally. Instead, I use questionnaire data on people's subjective life satisfaction as a direct measure of well-being. Using a large panel dataset of British households, I estimate well-being as a function of net income and hours worked, among standard control variables and time- and person-fixed effects. Based on parametric and nonparametric estimations, I find that well-being is highly concave in net income and single-peaked in working hours. These estimates allow me to determine people's well-being trade-off between working less and consuming more - and compare this to the actual trade-offs they make. The results indicate that low-income workers tend to work too little from a well-being point of view, whereas high-income workers tend to work too much. Compared to standard optimal tax simulations that do not take into account suboptimal behavior, this outcome endorses lower marginal tax rates at the bottom and higher marginal tax rates at the top of the income distribution.

To the best of my knowledge, this is the first study that combines the theoretically rigorous study of optimal taxation with empirical research on subjective well-being. There is a number of studies that determine optimal taxes when individuals' and government's preferences differ, but they stop short of empirically determining this difference. Similarly, there is a large number of studies on the determinants of well-being, but none of them integrate their findings into a proper optimal tax setting. ${ }^{3}$

My contribution to the literature on optimal tax theory is closely related to the contributions by Kanbur, Pirttilä, and Tuomala (2006) and Blomquist and Micheletto (2006), which both build on seminal work by Seade (1980). Kanbur, Pirttilä, and Tuomala, like Seade, derive the optimal nonlinear income tax schedule in a Mirrlees (1971) setting in which government's and individuals' preferences do not overlap. Blomquist and Micheletto do the same in the two-type optimal tax model of Stern (1982) and Stiglitz (1982). ${ }^{4}$ They show that the standard optimal tax schedule is supplemented with an additional term that depends on the difference between the individual's and government's marginal rates of substitution. They find, like I do, a reason for government to steer individual behavior by means of distortive taxation. I add to these earlier studies by deriving optimal taxes in terms of sufficient statistics - thereby allowing for a broader range of behavioral models and a more intuitive appeal - and by allowing for multidi-

\footnotetext{
${ }^{3}$ This is not to say that these studies did not concern themselves with public policy. Quite to the contrary, research on subjective well-being has always inspired policy advice. Probably the most prominent example is Layard (2011), who among other things calls for taxes to correct for people's status concerns and unanticipated habituation to changing living standards.

${ }^{4}$ Recent independent work by Farhi and Gabaix (2015) and Lockwood (2015) also study optimal labor income taxes when individuals suffer from behavioral biases.
} 
mensional heterogeneity, as well as by empirically measuring the degree to which people behave suboptimally.

The policy implications of individuals' suboptimal behavior have also been studied in the context of specific commodities. For example, O'Donoghue and Rabin (2006) study optimal 'sin taxes' on unhealthy goods that are consumed excessively by some part of the population. Allcott, Mullainathan, and Taubinsky (2014) show that if individuals harm their own well-being by overconsuming energy-inefficient commodities, corrective taxes are called for over and above the standard Pigouvian taxes on polluting commodities. Within a broader context, this paper is also related to the literature on optimal taxation in the presence of external effects (e.g., Sandmo, 1975; Jacobs and de Mooij, 2015). Instead of an externality, individual behavior exhibits an 'internality,' i.e., individuals do not take full account of their decisions' consequences for their own well-being. The optimal tax treatment of internalities, however, is very much comparable to optimal corrective taxation in the presence of externalities.

As I attempt to combine the theory of optimal taxation with the empirics of subjective well-being, my paper is also closely related to the empirical literature on the determinants of subjective well-being. This literature is surveyed by Clark, Frijters, and Shields (2008). The study by Layard, Mayraz, and Nickell (2008) is of special interest as they attempt to measure individuals' marginal well-being of income, which is a crucial ingredient of my optimal tax formula. However, to determine the nature of the trade-off between net income and leisure, one also needs to determine the marginal well-being of leisure. To my knowledge, only few studies include working effort or hours in their analysis of the determinants of life satisfaction, and with mixed results. For example, Pouwels, Siegers, and Vlasblom (2008) conclude that working hours negatively affect life satisfaction, while Knabe and Rätzel (2010), imposing a different functional form, fail to discern any effect. Booth and Van Ours (2008), using the same data as I do, also fail to find any relationship between hours worked and life satisfaction. I conjecture that this might be caused by not controlling for job changes and promotions. Indeed, if a promotion improves well-being and is generally followed by longer working weeks, as one would expect, the regression coefficient on hours worked might capture both a positive promotion effect and a negative hours effect. Controlling for this, I indeed find a robust single-peaked association between life satisfaction and working hours.

Finally, the notion that government ought to maximize a sum of individuals' wellbeing even if those individuals do not maximize well-being themselves is the subject of a long-standing philosophical debate. ${ }^{5}$ Bernheim and Rangel (2007) discuss the two schools of thought on the issue. One school only accepts preferences that are revealed

\footnotetext{
${ }^{5}$ A literary reference would be Fyodor Dostoyevsky's Notes From The Underground, in which the Underground Man laments: "You ... want to cure men of their old habits and reform their will in accordance with science and good sense. But how do you know, not only that it is possible, but also that it is desirable to reform man in that way?"
} 
through observed behavior as a normative guide for policy evaluation. The second school, to which the current study obviously belongs, in principle allows for deviations from revealed preferences as a normative guide. However, any deviation must be based on solid empirical evidence on how people make suboptimal decisions for themselves. As noted by Chetty (2015), such requirement should alleviate concerns about unjust paternalism - i.e., the concern that policy makers would be free to prioritize their own perceptions of an individual's well-being over those that are revealed by the individual's choices. Even when deviating from revealed preferences, policy makers ought to be bound by the type of empirical evidence that the current paper attempts to provide.

\section{Optimal income taxes}

\subsection{The dual approach}

Studies in optimal taxation traditionally apply the primal approach. They solve for the optimal allocation of consumption and labor supply, subject to resource and incentive compatibility constraints, and subsequently determine the tax schedule that implements this allocation (e.g., Mirrlees, 1971, 1976; Stiglitz, 1982; Diamond, 1998). However, to derive the optimal tax schedule in terms of sufficient statistics, it is more convenient to apply the dual approach and directly maximize social welfare with respect to the tax schedule. Earlier studies did so by heuristically studying tax perturbations (e.g., Saez, 2001; Piketty and Saez, 2013; Jacquet, Lehmann, and Van der Linden, 2013). This has the advantage of being more intuitive than the mechanism-design heavy primal approach, but is also mathematically less rigorous. In this paper, I apply the dual approach by first parameterizing the non-linear tax schedule, and subsequently maximizing social welfare with respect to this parameter. This method, first applied by Christiansen (1981, 1984) in the context of public good provision and commodity taxation, combines the intuitive appeal of heuristic tax perturbations with the mathematical rigor of the primal approach. ${ }^{6}$

\subsection{The tax schedule}

I consider an economy that consists of a mass-one continuum of individuals, $\mathcal{I}$. Labor income of individual $i \in \mathcal{I}$ is denoted by $z^{i} \equiv w^{i} l^{i}$, with $w^{i}$ his effective wage rate and $l^{i}$ his effective labor supply. I assume people differ in their wage rates, causing heterogeneity in both labor supply and income. Government can only observe, and thus only tax, labor income. Individual $i$ 's labor income tax is denoted by $T^{i}$. Since government has full control over the shape of the nonlinear tax schedule, an individual's tax burden is affected by both changes in his pre-tax labor income and reforms of the tax schedule.

\footnotetext{
${ }^{6}$ Also see Gerritsen (2015) for a more elaborate discussion on the dual approach to optimal taxation.
} 
This is captured by defining the tax burden as a function of labor income $z^{i}$ and a reform parameter $\kappa$ :

$$
T^{i} \equiv T\left(z^{i}, \kappa\right)=\tilde{T}\left(z^{i}\right)+\kappa \tau\left(z^{i}\right) .
$$

The tax schedule is assumed to be twice differentiable in $z^{i}$. I refer to $\tau(\cdot)$ as the nonlinear reform function. The reform parameter can take on any arbitrary value and the reform function any arbitrary form; $\tilde{T}(\cdot)$ ensures that $T(\cdot, \kappa)$ equals a given pre-reform tax schedule.

A tax reform is modelled as a change in the reform parameter $\kappa$. Such reform affects the tax burden of individual $i$ both directly by altering the tax schedule, and indirectly as the individual adjusts his labor income. This can be seen by taking the derivative of eq. (1) with respect to the reform parameter:

$$
\frac{\mathrm{d} T^{i}}{\mathrm{~d} \kappa}=\tau\left(z^{i}\right)+T_{z}^{i} \cdot \frac{\mathrm{d} z^{i}}{\mathrm{~d} \kappa}
$$

where a subscript denotes a partial derivative, such that $T_{z}^{i} \equiv T_{z}\left(z^{i}, \kappa\right)$ is the marginal tax rate for a person with income level $z^{i}$. The first term in eq. (2) gives the direct effect of the tax reform, as individual $i$ 's tax burden is raised by $\tau\left(z^{i}\right)$. The second term gives the effect of the reform-induced change in individual $i$ 's labor income, which equals the change in gross income multiplied by the marginal tax rate.

The validity of eq. (2) requires that labor income is differentiable with respect to the reform parameter. This assumption is crucial: it implies that marginal changes in taxes lead to marginal changes in behavior. ${ }^{7}$ Allowing for discrete changes in individuals' tax bases would significantly complicate the analysis. Below, I specify the remainder of the model - individual behavior and well-being, the social objective, and the government budget - in terms of the tax schedule, and thus in terms of $\kappa$. Given the differentiability assumption, I can determine the marginal effects of tax reforms by taking derivatives with respect to $\kappa$, and substituting for any particular reform of interest $\tau(\cdot)$.

\subsection{Individual behavior}

Individuals' behavioral responses to a change in the tax rate are captured by the elasticities of their taxable income. For simplicity, I assume away any income effects, so that individuals only adjust their tax bases in response to changes in marginal tax rates. This is not crucial for the analysis - in fact, it is straightforward to allow for income effects

\footnotetext{
${ }^{7}$ In a standard model with individuals that maximize utility (though not necessarily well-being), this implies that individual indifference curves are never tangent to the budget curve at more than one point, and that an extensive labor supply decision is ruled out. Jacquet and Lehmann (2015) present sufficient conditions for this to hold in the tax optimum when people are heterogeneous both with respect to income and, conditional on income, with respect to behavioral elasticities.
} 
- but simplifies its exposition. ${ }^{8}$ The (compensated and uncompensated) net-of-tax-rate elasticity of individual $i$ 's tax base can be written as: ${ }^{9}$

$$
e^{i} \equiv-\frac{\mathrm{d} z^{i}}{\tau_{z}\left(z^{i}\right) \mathrm{d} \kappa} \frac{1-T_{z}^{i}}{z^{i}}
$$

Notice that I allow behavioral elasticities to be individual-specific, and even to vary across individuals with identical labor income. The elasticities in eq. (3) function as sufficient statistics in the derivation of the optimal nonlinear income tax. The Appendix shows how $e^{i}$ could be written in terms of deeper structural parameters within the context of the canonical labor-supply model. However, the sufficiency of $e^{i}$ does not rely on the validity of this specific model, as it might potentially be a sufficient statistic under a wide range of behavioral models. This is especially useful for the purposes of this study, as it allows me to remain agnostic about the exact reason for individuals' misoptimization.

\subsection{Individual well-being}

The well-being of individual $i$ is assumed to be a function of net income and labor effort, given by $g^{i}\left(z^{i}-T^{i}, z^{i} / w^{i}\right)$, which I allow to differ across people. Typically, we think of a person's well-being as increasing in net income and decreasing in labor effort, thus creating a trade-off between consuming more and working less. If an individual does not choose the income that maximizes his well-being, this drives a wedge between his marginal cost and benefit of earning an additional unit of income. I define this wedge, for individual $i$, as follows:

$$
\omega^{i} \equiv \frac{-g_{l}^{i} / w^{i}}{g_{c}^{i}}-\left(1-T_{z}^{i}\right)
$$

where $g_{l}^{i}$ measures the marginal well-being of labor effort, and $g_{c}^{i}$ the marginal well-being of consumption. As with the elasticities, I allow $\omega^{i}$ to be heterogeneous across individuals, even if they earn the same income.

Notice that $-g_{l}^{i} / w^{i}$ measures individual $i$ 's marginal cost of earning an additional unit of income. Dividing by $g_{c}^{i}$, the first term of eq. (4) expresses this cost in monetary terms.

\footnotetext{
${ }^{8}$ In a separate Appendix, available upon request, I derive the optimal nonlinear tax schedule while allowing for income effects.

${ }^{9}$ Within the literature on optimal nonlinear income taxation there is some ambiguity on the proper definition of the elasticity of taxable income. For example, Saez (2001) measures the elasticity as the change in income along a linearized budget line. This definition filters out the effect of 'bracket creep,' i.e., the fact that the change in income itself further alters a person's marginal tax rate if the tax schedule is nonlinear. Contrary to this, Jacquet, Lehmann, and Van der Linden (2013) define the elasticity as the change of income along the actual budget line, which incorporates the second-round effect of bracket creep. The elasticity in eq. (3) corresponds with the latter definition. Ultimately, the advantage of this definition is that it allows me to write the optimal income tax in terms of the actual income distribution, rather than a 'virtual' income distribution as in Saez (2001).
} 
The marginal benefit of earning an additional unit of income simply equals the marginal net-of-tax rate, given by the second term in eq. (4). If the marginal cost of earning more income exceeds the marginal benefit, individual $i$ works too much, as he could increase his well-being by simply working less. Conversely, if the marginal cost is smaller than the marginal benefit, individual $i$ works too little and could increase his well-being by working more. For this reason, I refer to $\omega^{i}$ as the degree to which individual $i$ works too much. Intuitively, his labor supply would have been justified on well-being grounds had his marginal tax rate been $\omega^{i}$ percentage points lower. For example, if $\omega^{i}=\frac{1}{2}$, individual $i$ works 'as if' his marginal tax rate is fifty percentage points lower than it actually is; if $\omega^{i}=-\frac{1}{2}$, he works 'as if' his marginal tax rate if fifty percentage points higher.

\subsection{The social objective}

I consider a welfarist social objective, which implies that social welfare can be written as a weighted sum (integral) of all individuals' well-being:

$$
\mathcal{W} \equiv \int_{\mathcal{I}} \gamma^{i} g^{i}\left(z^{i}-T^{i}\left(z^{i}, \kappa\right), \frac{z^{i}}{w^{i}}\right) \mathrm{d} i,
$$

with individual-specific weights $\gamma^{i}$. In the case of utilitarian social preferences, $\gamma^{i}=\gamma$ for all $i \in \mathcal{I}$. The social welfare effects of a tax reform are obtained by taking the derivative of eq. (5) with respect to the reform parameter. Substituting for $\omega^{i}$ from eq. (4) yields:

$$
\frac{\mathrm{d} \mathcal{W}}{\mathrm{d} \kappa}=-\int_{\mathcal{I}} \gamma^{i} g_{c}^{i}\left(\tau\left(z^{i}\right)+\omega^{i} \cdot \frac{\mathrm{d} z^{i}}{\mathrm{~d} \kappa}\right) \mathrm{d} i
$$

The first term within brackets represents the reform's cost of reducing people's taxable income by $\tau\left(z^{i}\right)$. Multiplying by $g_{c}^{i}$ yields its effect on individuals' well-being; multiplying by $\gamma^{i}$ yields its effect on social welfare. The second term within brackets represents the reform's effect on individuals' labor supply decisions. An increase in labor supply is detrimental for an individual's well-being if he works too much $\left(\omega^{i}>0\right)$ and beneficial if he works too little $\left(\omega^{i}<0\right)$. Expressed in monetary terms, higher labor income leads to a well-being loss of $\omega^{i}$. Multiplication by $\gamma^{i} g_{c}^{i}$ yields the effect on social welfare. Compared to traditional studies of optimal taxation, the latter term is novel. After all, if individuals maximize well-being, $\omega^{i}=0$ and the term vanishes.

Substituting for the definition of the behavioral elasticities from eq. (3), I can alternatively rewrite eq. (6) as:

$$
\frac{\mathrm{d} \mathcal{W}}{\mathrm{d} \kappa}=-\int_{\mathcal{I}} \gamma^{i} g_{c}^{i}\left(\tau\left(z^{i}\right)-\frac{\omega^{i}}{1-T_{z}^{i}} \cdot z^{i} e^{i} \tau_{z}\left(z^{i}\right)\right) \mathrm{d} i .
$$

Thus, an increase in a person's total tax burden, $\tau\left(z^{i}\right)>0$, leads to mechanical well-being 
losses due to a drop in disposable income (first term within brackets). An increase in a person's marginal tax rate, $\tau_{z}\left(z^{i}\right)>0$, leads him to work less and therefore increases well-being if he works too much, but reduces well-being if he works too little (second term within brackets). The latter effect is stronger for larger degrees of misoptimization $\left(\left|\omega^{i}\right|\right)$ and for larger labor supply responses, i.e., for higher levels of the elasticity of taxable income.

\subsection{Government budget}

The government is restricted in its policy options by the amount of available resources. The government budget is given by a simple sum (integral) of all individuals' income taxes:

$$
\mathcal{B} \equiv \int_{\mathcal{I}} T\left(z^{i}, \kappa\right) \mathrm{d} i
$$

The effects of a tax reform on the government's budget are obtained by taking the derivative of eq. (8) with respect to the reform parameter:

$$
\frac{\mathrm{d} \mathcal{B}}{\mathrm{d} \kappa}=\int_{\mathcal{I}}\left(\tau\left(z^{i}\right)+T_{z}^{i} \cdot \frac{\mathrm{d} z^{i}}{\mathrm{~d} \kappa}\right) \mathrm{d} i .
$$

As usual, a tax reform has two effects on government revenue: a mechanical effect and a behavioral effect. The mechanical effect is given by the first term within brackets, and measures the direct revenue effect of raising individuals' tax burdens by $\tau\left(z^{i}\right)$. The behavioral effect is given by the second term within brackets. If the reform causes individuals to increase their tax base, this raises government revenue at a rate equal to the marginal tax rate, $T_{z}^{i}$.

Substituting for the behavioral elasticities from eq. (3) allows me to rewrite eq. (9) as:

$$
\frac{\mathrm{d} \mathcal{B}}{\mathrm{d} \kappa}=\int_{\mathcal{I}}\left(\tau\left(z^{i}\right)-\frac{T_{z}^{i}}{1-T_{z}^{i}} \cdot z^{i} e^{i} \tau_{z}\left(z^{i}\right)\right) \mathrm{d} i .
$$

Thus, an increase in a person's total tax burden, $\tau\left(z^{i}\right)>0$, leads to mechanical revenue gains (first term within brackets). An increase in a person's marginal tax rate, $\tau_{z}\left(z^{i}\right)>0$, leads to revenue losses through tax-base erosion, provided that marginal tax rates are positive (second term within brackets). The latter effect is increasing in the marginal tax rate and in the elasticity of taxable income. 


\subsection{Optimal taxes}

An increase in the government's budget implies it can further raise social welfare by lowering taxes. Denoting the social marginal value of public goods by $\lambda$, a reform's total effect on social welfare can be written as $\frac{\mathrm{d} \mathcal{W} / \lambda}{\mathrm{d} \kappa}+\frac{\mathrm{d} \mathcal{B}}{\mathrm{d} \kappa}$. I define individual $i$ 's welfare weight, or social marginal value of consumption, as $a^{i} \equiv \gamma^{i} g_{c}^{i} / \lambda$. I assume that welfare weights are decreasing with income - either because well-being is concave in consumption or because government cares more for the poor - implying that redistribution from rich to poor enhances social welfare. Combining eqs. (7) and (10) allows me to write:

$$
\frac{\mathrm{d} \mathcal{W} / \lambda}{\mathrm{d} \kappa}+\frac{\mathrm{d} \mathcal{B}}{\mathrm{d} \kappa}=\int_{\mathcal{I}}\left(\left(1-a^{i}\right) \tau\left(z^{i}\right)-\frac{T_{z}^{i}-a^{i} \omega^{i}}{1-T_{z}^{i}} \cdot z^{i} e^{i} \tau_{z}\left(z^{i}\right)\right) \mathrm{d} i
$$

A reform's total effect on social welfare can be subdivided in those due to changes in people's tax burden and those due to changes in marginal tax rates. Higher tax burdens raise government revenue but reduces people's well-being. Higher marginal tax rates reduce government revenue through tax base erosion and might lead to well-being gains or losses, depending on whether people work too much or too little. If taxes are set optimally, total social welfare should remain unaffected by any marginal tax reform. Optimal taxes are thus obtained by equating eq. (11) to zero for every possible reform function $\tau(z)$.

\subsubsection{Raising the tax burden for all}

To further characterize optimal taxes, I consider two specific tax reforms. The first simply raises the tax burden for every individual by $\mathrm{d} \kappa$, such that $\tau\left(z^{i}\right)=1$ and $\tau_{z}\left(z^{i}\right)=0$ for all $i$. Substituting this into eq. (11) and equating it to zero yields the following optimality condition:

$$
\int_{\mathcal{I}} a^{i} \mathrm{~d} i=1
$$

The left-hand side gives the cost of equally reducing every person's disposable income, whereas the right-hand side gives the associated government revenue gains. As marginal taxes remain unchanged, there is no behavioral response to the reform. Eq. (12) gives the standard result from Mirrleesian optimal taxation that the government should on the margin be indifferent between resources owned by the public or private sectors. It also implies that the population's average welfare weight equals unity.

\subsubsection{Raising marginal taxes}

The second tax reform raises the tax burden by $\mathrm{d} \kappa$ for every individual that earns labor income above a certain level $z^{\iota}$. This is captured by a reform function that equals $\tau(z)=1$ 
for everyone with income $z>z^{\iota}$ and $\tau(z)=0$ for everyone with income $z \leq z^{\iota}$. This implies that the marginal tax rate at income level $z^{\iota}$ is increased, $\tau_{z}\left(z^{\iota}\right)>0$, whereas marginal taxes for all other income levels remain constant. To determine the exact increase of the marginal tax rate at $z^{\iota}$, notice that the definition of the derivative implies that $\tau_{z}\left(z^{\iota}\right) \equiv \frac{\tau\left(z^{\iota}+\mathrm{d} z\right)-\tau\left(z^{\iota}\right)}{\mathrm{d} z}$. Substituting for $\tau\left(z^{\iota}+\mathrm{d} z\right)=1$ and $\tau\left(z^{\iota}\right)=0$ yields $\tau_{z}\left(z^{\iota}\right)=$ $\frac{1}{\mathrm{~d} z}$. By substituting the reform into eq. (11), I obtain the following optimality condition:

$$
\int_{\mathcal{I}: z^{i}=z^{\iota}}\left(\frac{T_{z}^{\iota}-a^{i} \omega^{i}}{1-T_{z}^{\iota}}\right) z^{\iota} e^{i} \frac{\mathrm{d} i}{\mathrm{~d} z}=\int_{\mathcal{I}: z^{i}>z^{\iota}}\left(1-a^{i}\right) \mathrm{d} i .
$$

Notice that the integral on the left-hand side is taken over all individuals that earn an income equal to $z^{\iota}$, whereas the integral on the right-hand side is taken over all individuals that earn more than $z^{\iota}$. The left-hand side of eq. (13) gives the distortive costs of the reform: individuals with income $z^{\iota}$ face higher marginal taxes, which leads to revenue losses through tax base erosion and either improves their well-being if they work too much, or reduces their well-being if they work too little. The right-hand side of eq. (13) gives the redistributive benefits of the tax reform. The reform leads to higher government revenue - which can be used for redistribution - but also to well-being losses for people earning more than $z^{\iota}$. As welfare weights are assumed to be decreasing with income, eq. (12) implies that the redistributive gains of the tax reform are strictly positive as long as $z^{\iota}$ is in the interior of the income distribution.

To gain more insight into the optimal marginal tax rate, it is useful to rewrite eq. (13) in terms of the income distribution. Specifically, let the cumulative distribution function $H(z) \equiv \int_{\mathcal{I}: z^{i}<z} \mathrm{~d} i$ measure the proportion of people with income below $z$. This implies that $\mathrm{d} H(z)=\int_{\mathcal{I}: z^{i}=z} \mathrm{~d} i$. I furthermore define the income density as $h(z) \equiv \mathrm{d} H(z) / \mathrm{d} z$. For simplicity, I assume that the degree to which people work too much, the welfare weight, and the elasticity are uncorrelated for individuals with the same labor income. This allows me to write their income-conditional averages out of the integral on eq. (13)'s left-hand side. Below, I discuss how relaxing this assumption affects the results. I can now rewrite eq. (13) as follows:

$$
\frac{T_{z}^{\iota}-\bar{a}^{\iota} \bar{\omega}^{\iota}}{1-T_{z}^{\iota}}=\frac{1}{\bar{e}^{\iota}} \cdot \frac{1-H\left(z^{\iota}\right)}{h\left(z^{\iota}\right) z^{\iota}} \cdot\left(1-\frac{\int_{\mathcal{I}: z^{i}>z^{\iota}} a^{i} \mathrm{~d} i}{1-H\left(z^{\iota}\right)}\right),
$$

where I define $\bar{e}^{\iota}$ as the average elasticity for all individuals with labor income $z^{\iota}$, and do the same for $\bar{a}^{\iota}$ and $\bar{\omega}^{\iota}$. The left-hand side of eq. (14) gives the average wedge on labor income for income level $z^{\iota}$, i.e., the marginal social welfare of individuals' net income, averaged over all individuals with income $z^{\iota}$. To see this, note the following: to earn an additional unit of net income, individual $\iota$ needs to earn $\frac{1}{1-T_{z}^{\iota}}$ more gross income. The additional gross income yields government revenue at a rate $T_{z}^{\iota}$; hence the tax wedge 
$\frac{T_{z}^{\iota}}{1-T_{z}^{\iota}}$. The additional gross income also lowers the individual's well-being by $\omega^{\iota}$, which is socially valued at a rate $a^{\iota}$. This yields the well-being wedge $\frac{-a^{\iota} \omega^{\iota}}{1-T_{z}^{\iota}}$. Averaged over all individuals with income $z^{\iota}$, the sum of the two wedges gives the total wedge on the left-hand side of eq. (14). The total wedge is a measure of the labor supply distortions at a certain income level. Notice that even in the absence of any taxation, labor supply might be distorted if individuals do not maximize their well-being.

The right-hand side of eq. (14) is virtually identical to the standard result for the optimal tax wedge in the absence of income effects (e.g., Saez, 2001; Piketty and Saez, 2013). ${ }^{10}$ The only difference, as in Jacquet and Lehmann (2015), is that the first term gives the inverse of the average elasticity of taxable income for people earning $z^{\iota}$-whereas in the classical result, individuals with the same income are assumed to have identical elasticities. The optimal wedge contains three terms that function as sufficient statistics: an elasticity term, an income distribution term, and a redistribution term. The first term indicates that a larger elasticity of taxable income makes taxation more distortive and thus lowers the optimal wedge. The numerator of the second term indicates that a larger number of people with income above $z^{\iota}$ allows the marginal income tax to redistribute more income, raising the optimal wedge. The denominator indicates that a larger income density at $z^{\iota}$ raises the distortion of taxation and therefore lowers the optimal wedge. The third term indicates that lower welfare weights for those with income above $z^{\iota}$ cause larger redistributive gains of the marginal income tax, and therefore raises the optimal wedge. The right-hand side of eq. (14) has excessively been studied in earlier literature and I refer to previously cited studies for a more detailed discussion.

\subsubsection{Interpretation}

For a given optimal wedge on labor income, the left-hand side of eq. (14) shows that optimal marginal taxes are increasing with the degree to which individuals work too much. ${ }^{11}$ The intuition for this result is clear. Higher marginal taxes cause people to reduce their labor supply. While this leads to revenue losses, as measured by the tax wedge, it also affects individuals' well-being, as measured by the well-being wedge. It raises individuals' well-being if on average they work too much, and reduces their wellbeing if they work too little. This generates a corrective argument for distortive taxation:

\footnotetext{
${ }^{10}$ Taking into account income effects would only slightly alter the right-hand side of eq. (13). The only adjustment needed is to redefine $a^{i}$ as the social marginal value of individual $i$ 's income rather than his consumption (cf., Diamond, 1975), thereby incorporating income effects on government revenue and well-being. Similarly, the definition of $a^{i}$ could be adjusted to incorporate a labor participation decision - see, e.g., Jacquet, Lehmann, and Van der Linden (2013).

${ }^{11}$ Of course, the optimal wedge on labor income - i.e., the right-hand side of eq. (14) - as well as the degree to which people work too much are both endogenous to the tax schedule. Empirical evidence on the four sufficient statistics based on the actual tax system might therefore differ from their values in the tax optimum. While this necessitates caution when drawing quantitative conclusions about the optimal tax system, eq. (14) can inform us about the desirable direction of reform. If the right-hand side of eq. (14) is larger than the left-hand side, it is desirable to raise marginal taxes.
} 
marginal taxes should be set to bring individuals' labor supply more in line with their well-being bliss point. To achieve this, optimal marginal taxes are increasing with the degree to which individuals work too much.

The corrective argument for taxation implies that distortive taxes are generally nonzero in the optimum, even in the absence of redistributive social preferences. To see this, consider the case in which welfare weights are positive but identical for every individual. As a result, the right-hand side of eq. (14) vanishes. But as the left-hand side shows, as long as individuals make suboptimal decisions, marginal taxes should be employed to correct their behavior. ${ }^{12}$ Furthermore, eq. (14) shows that negative marginal income taxes might be part of the optimal tax system. This is again easiest to see in the absence of redistributive concerns. In that case, negative marginal income taxes are always optimal for income levels at which individuals on average work too little from a well-being point of view.

As can furthermore be seen from eq. (14), the corrective argument for distortive taxation is especially strong for individuals with a high welfare weight. After all, the more government cares about an individual's well-being, the more important it becomes to correct his behavior and bring him closer to his well-being bliss point. The shape of the social welfare function therefore importantly determines the strength of the corrective argument. With utilitarian social preferences, the strength of the corrective argument is determined by the individual's marginal well-being of income. With decreasing marginal well-being of income, the importance of the corrective argument therefore tends to decrease with income. In the extreme case of Rawlsian social preferences, in which government only cares about the worst-off individual, everyone but the worst off has a welfare weight $a^{i}=0$ so that the corrective argument ceases to play a role. The intuition is straightforward: if government only cares about the worst-off, it is optimal to extract as many resources from the rest as possible with no regard for their well-being.

In going from eq. (13) to (14), I assumed that, for individuals with the same income, the degrees to which they work too much is uncorrelated with their elasticities of taxable income and their welfare weights. But there are a number of potentially interesting scenarios in which this assumption does not hold. For example, it might well be that people who misoptimize are less responsive to price signals and therefore have lower elasticities. ${ }^{13}$ This tends to lower the product $\omega^{i} e^{i}$ on the left-hand side of eq. (13), thereby reducing the importance of the corrective argument. After all, if misoptimizers

\footnotetext{
${ }^{12}$ This point also casts doubt on the validity of the fundamental theorems of welfare economics. If we define an allocation to be Pareto efficient if no person's well-being can be improved without harming the well-being of someone else, it is clear that a competitive equilibrium without distortive taxation is not Pareto efficient if individuals make suboptimal decisions. Alternatively, if we define Pareto efficiency in terms of revealed preferences, rather than well-being, the fundamental theorems are upheld, but Pareto efficiency ceases to be a compelling normative requirement.

${ }^{13}$ Chetty et al. (2014) make an argument to this effect within the context of subsidies for retirement savings, see also Chetty (2015).
} 
are less responsive to price signals, marginal taxes become less useful as a tool to correct their suboptimal behavior. Similarly, it might be that government cares more about the 'hard-working' people that work too much than about the 'lazy' people that work too little. This reduces the corrective argument for people that work too little and strengthens the corrective argument for those who work too much. As a result, the expectation of the product $a^{i} \omega^{i}$ on the left-hand side of eq. (13) increases, leading to higher optimal marginal taxes.

\subsubsection{Optimal top tax rate}

Eq. (14) also allows me to derive the optimal tax rate at the top bracket of the income distribution (cf., Saez, 2001). For this, I assume that the top is well-described by a Pareto distribution with parameter $p$. This implies that $\frac{1-H(\bar{z})}{\bar{z} h(\bar{z})}=\frac{1}{p}$, where $\bar{z}$ stands for any income level at the top of the distribution. I furthermore assume that the average elasticity $\bar{e}^{i}$, and the average welfare weight $\bar{a}^{i}$ converge to $\bar{e}$ and $\bar{a}$, respectively. Substituting into eq. (14), yields the following condition for the optimal top tax rate: ${ }^{14}$

$$
\frac{\bar{T}_{z}-\bar{a} \bar{\omega}}{1-\bar{T}_{z}}=\frac{1-\bar{a}}{p \bar{e}}
$$

As usual, the optimal top tax rate is decreasing in the elasticity of taxable income, and increasing in the thickness of the tail of the income distribution (which is inversely related to the Pareto parameter). Provided that the welfare weight of top earners is positive, the top tax rate is furthermore increasing with the degree to which they work too much. This leaves the effect of the welfare weight ambiguous. Higher welfare weights for the top imply lower redistributive gains of taxation, as shown by the right-hand side of eq. (15). However, if top earners work too much from a well-being point of view, a higher welfare weight increases the importance of the corrective argument to raise taxes. Thus, if top earners are especially prone to working too much, it might well be that larger welfare weights for the top lead to a higher optimal top tax rate.

\footnotetext{
${ }^{14}$ Eq. (14) is meant to clarify the impact of individual misoptimization on the optimal tax rate at the top. For a quantitative exploration of the optimal top tax rate, income effects should also be taken into account, see also footnote 8. Moreover, Jacquet and Lehmann (2015) stress that the asymptotic average elasticity is not generally independent of the top tax rate when people with the same income level have different elasticities. In that case, $\bar{e}$ refers to the value in the optimum, which cannot simply be deduced from observations outside the optimum.
} 


\section{How far away are people from their bliss points?}

\subsection{Measuring suboptimal behavior}

The above analysis calls for positive corrective taxes for those who work too much and negative corrective taxes for those who work too little. But how to measure whether people work too much or too little? One way is to simply ask them. Asking people to reflect on their usual behavior - outside of the context in which this behavior typically takes place - might allow them to provide an assessment that is less affected by behavioral biases. Thus asking people whether they are satisfied with their current number of working hours might provide some information on whether they are likely working too much or too little. As part of the British Household Panel Survey (BHPS), which I discuss below, one question asks whether the respondents would prefer working fewer, more or the same number of hours at their current hourly wage rate. Figure 1 shows descriptive statistics of the answers for 85,873 observations. While most people prefer working the same number of hours, a sizeable share indicates preferring to change their number of hours. Plotting the percentage of people that prefer to work fewer or more hours against gross household labor income yields the second panel of Figure 1.

For most of the income distribution, there are more people who prefer working fewer hours than there are people who prefer working more hours. However, the share of people who prefer to work fewer hours is clearly increasing with gross labor income, while the share of people who prefer to work more hours is declining with income. This suggests that optimal corrective taxes might be increasing with household labor income. Stated preference should, however, be interpreted with caution. They might be subject to the same biases as people's revealed preferences. For example, if an individual works too much because he overestimates the well-being benefits of pursuing a successful career, or because he misunderstands the slope of his own budget curve, his stated preferences might be affected by these same biases. Moreover, the stated preferences are not incentivized, so even if they are unbiased it is impossible to infer the importance of individuals' misoptimization - i.e., how much well-being would improve if the stated preferences were to come true.

The theoretical analysis above indicated that it is this latter measure that is crucial for the welfare analysis. I showed that the standard optimal tax formula is adjusted to include a new sufficient statistic, $\omega^{i}$, which measures the degree to which an individual works too much. In the remainder of this section, I attempt to measure this statistic. Its definition in eq. (4) shows that it consists of four ingredients: the effects of consumption and leisure on the individual's well-being, along with his wage and marginal tax rates. To obtain the former, I use survey data on people's general life satisfaction as an approximation of their well-being. Using panel data on life satisfaction, I estimate a well-being function 

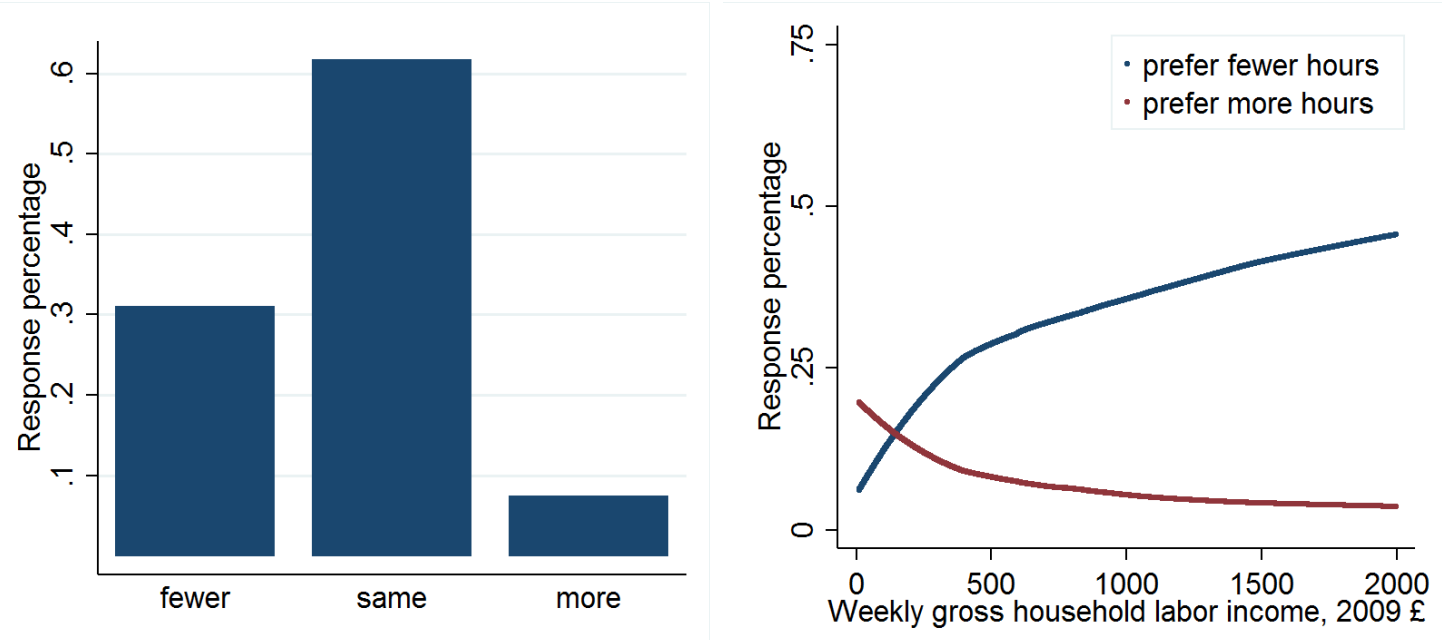

Figure 1: Stated preferences for working hours, histogram and averages over income

to determine the well-being effects of consumption and leisure. Together with data on wages and marginal taxes, this allows me to obtain a measure of $\omega^{i}$.

Besides the extent to which individuals work too much, I am interested in the total wedge on labor income as given by the left-hand side of eq. (14). On the basis of the theoretical analysis, I concluded that the total wedge rather than just the tax wedge should be taken into account in judgments concerning the optimality of a tax system. For this reason, I am especially interested in how much the total wedge on labor earnings deviates from the tax wedge. This gives an indication of the extent to which wedges on labor earnings are habitually over- or underestimated by assuming that individuals maximize well-being. The analysis below thus provides a qualification to studies that draw conclusions on the optimality of current tax systems on the basis of the tax wedge alone.

Naturally, the assumption that life satisfaction perfectly corresponds with well-being can and should be subjected to criticism. Indeed, Köszegi and Rabin (2008) argue that both life-satisfaction measures and choice-based measures (i.e., revealed preferences) contain unique information on a person's true well-being. The ideal measure of well-being would therefore make use of both types of data. But while there are numerous studies on optimal taxation that focus on revealed preferences, there are none that focus on subjective well-being. Even if life satisfaction is not the ideal measure of well-being, I therefore consider the analysis of this section as a useful first step towards evaluating income taxes on the basis of a more holistic welfare criterion. 


\subsection{Data and strategy}

\subsubsection{Dataset and sample selection}

The empirical analysis uses data from the BHPS, which includes information on numerous variables for a representative sample of individuals over consecutive years. Data are available for every year between 1991 and 2008, but a question on subjects' well-being has been available since 1996, with the exception of 2001. Thus, I am able to use data for the years 1996 to 2000 and 2002 to 2008, making for a raw sample of 27,699 unique individuals over a period of up to 12 years, with on average 6.2 years of data per individual. In order to obtain a relatively homogeneous group of people without losing too many observations, and to limit the likelihood of omitted variable biases in my empirical analysis, I impose further restrictions on this sample.

For homogeneity, I restrict the sample to heads of household, who are employed, without children, and of prime working-age between 25 and 59 years old. ${ }^{15}$ In addition, I only include people if they have the same job function as in the preceding year, i.e., I exclude people whose function has changed, whether this was due to promotion or demotion, due to a change of company, or because of new entrance into the labor market. I do this because job changes are likely to have a direct impact on life satisfaction, while at the same time affecting the number of hours worked. As a result, without controlling for job changes, the effect of those changes on life satisfaction would be absorbed by the coefficient of the number of working hours. ${ }^{16}$ Indeed, failure to control for changes of job function might well be an important reason why some previous studies on life satisfaction did not find a significant effect of hours worked (e.g., Booth and Van Ours, 2008). The remaining sample contains 4,194 unique individuals, with an average of 3.2 observations per individual.

\subsubsection{Measuring well-being}

An individual's well-being is measured by the response when asked about satisfaction with his or her life. The specific question asked is:

How dissatisfied or satisfied are you with your life overall?

Possible answers range from 1 to 7, with 1 labeled "Not satisfied at all," and 7 labeled "Completely satisfied." As discussed above, I assume that the answer to this question

\footnotetext{
${ }^{15}$ For the definition of the head of household, the BHPS follows the General Household Survey, i.e., the principal owner or renter of property, and (where there is more than one), the male taking precedence, and (where there is more than one potential head of household of the same sex), the eldest taking precedence.

${ }^{16}$ Instead of excluding job changers from the sample, I also directly controlled for changes in job function. This does not change results much. I prefer excluding these observations from the analysis entirely, because I cannot observe the reason for the job change, e.g., whether it was due to a promotion or a demotion, which is potentially important.
} 

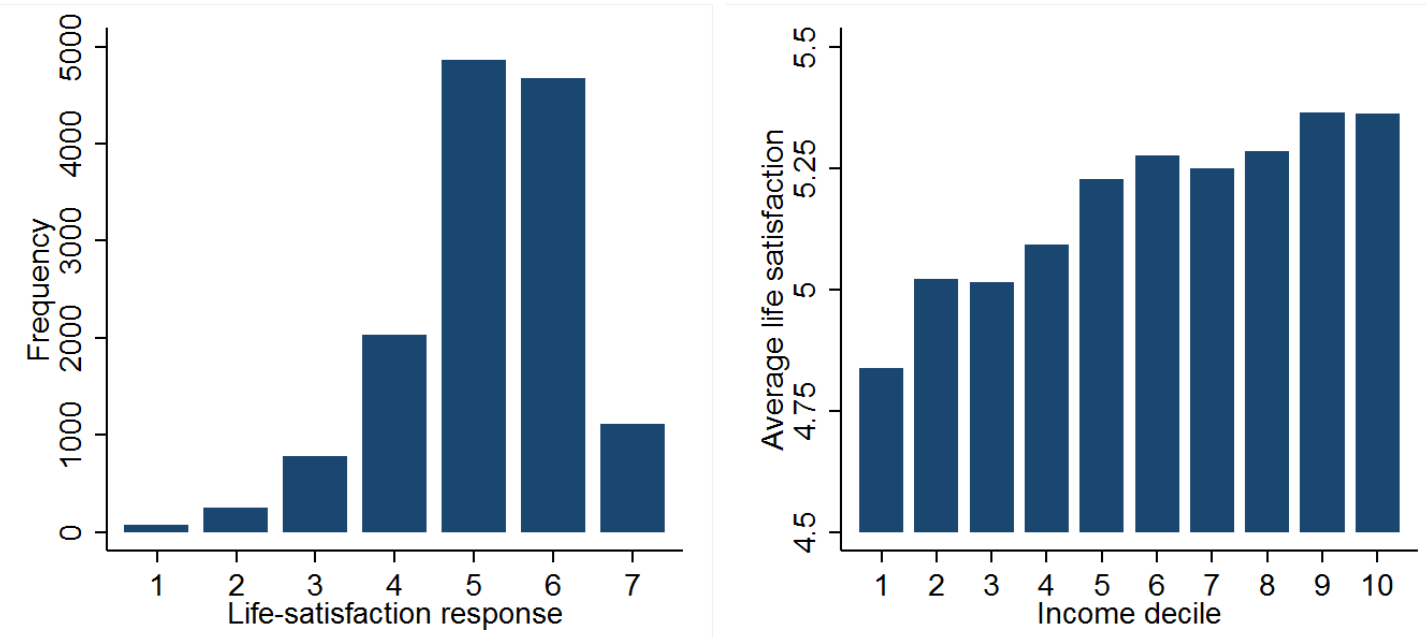

Figure 2: Histogram of life satisfaction and average life satisfaction by income decile
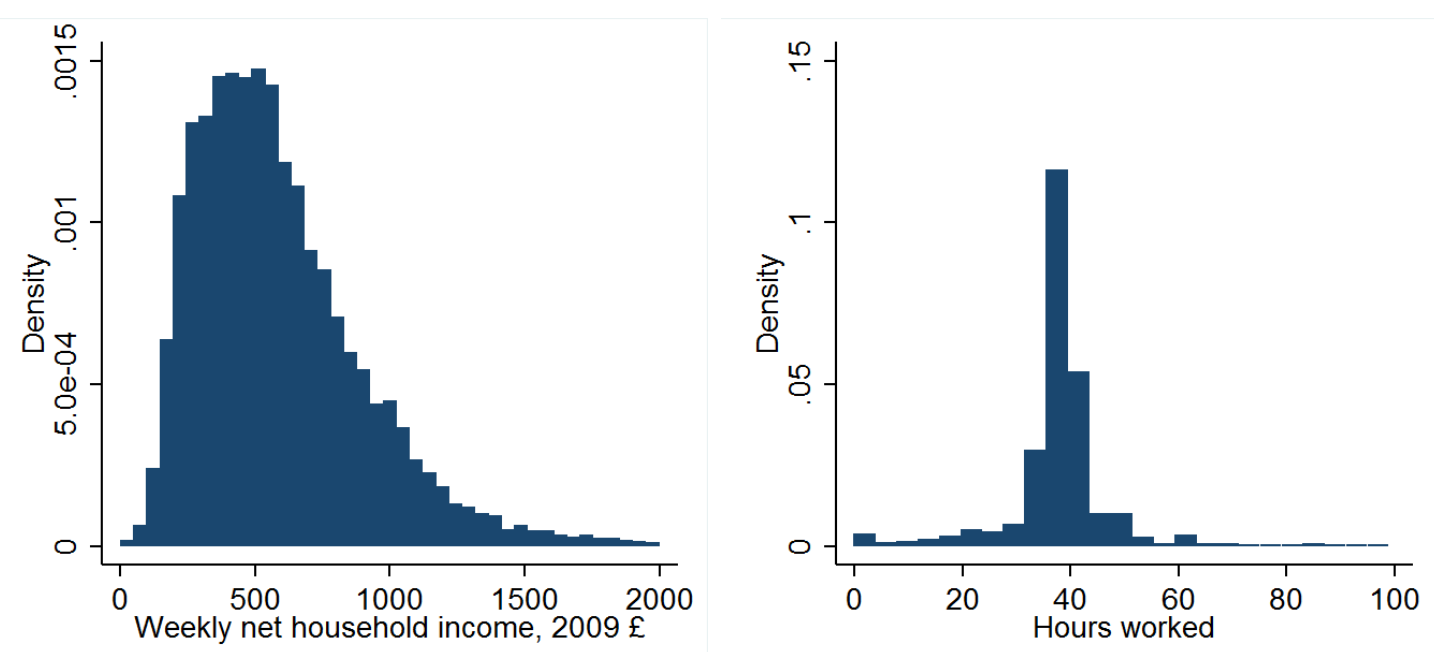

Figure 3: Densities of real net household income and hours worked

reflects the well-being of the person answering the questionnaire, and is thus taken to be the empirical measure of $g^{i}$. Figure 2 contains two panels that describe the data contained in the life satisfaction variable. The first panel illustrates the frequency at which a certain life satisfaction score is given as answer. The second panel illustrates the average life satisfaction score for each decile of net household income.

\subsubsection{Explanatory variables}

Since I want to obtain the well-being effects of consumption and leisure, the most important explanatory variables are measures of consumption and working hours. As an approximation of consumption I choose to follow Layard, Mayraz, and Nickell (2008) by using total real net household income. Naturally, one would like to use permanent income when explaining overall life satisfaction. However, in the absence of data on permanent income I need to rely on current income. Some, but most likely not all, of the bias that 
originates from my reliance on current income is eliminated by the sample restrictions on age. Income is measured at constant household costs, and includes income from labor, investments, benefits, pension, and transfers, net of taxes. I choose not to normalize the income variable by using equivalence scales to correct for the size of the household. The reason I do not do this is because the choice of the particular equivalence scale is always a controversial issue, and because for my main specification, in which income enters the well-being equation logarithmically, the equivalence scale is in any case absorbed by the marital-status dummies. The first panel in Figure 3 illustrates the density of net weekly household income.

The second crucial explanatory variable measures the number of hours a person works in a normal week. The second panel in Figure 3 illustrates the density of these weekly hours worked. Not surprisingly, the amounts of working hours are mostly concentrated around forty hours of work per week though enough variation remains. Other explanatory variables I use include age dummies, subjective health evaluation dummies (answers ranging from 1, "very poor", to 5, "excellent"), year dummies, and marital status dummies. On top of that I include person-fixed effects to capture the influence of all person-specific time-invariant variables.

\subsubsection{Empirical strategy}

The empirical strategy of this section is largely in line with that of Layard, Mayraz, and Nickell (2008). The main results follow from estimating the following linear equation:

$$
g^{i t}=a_{0} \ln c^{i t}+a_{1} l^{i t}+a_{2}\left(l^{i t}\right)^{2}+\sum_{j} b_{j} x_{j}^{i t}+\zeta^{t}+\zeta^{i}+v^{i t}
$$

where superscripts $i$ and $t$ denote individual $i$ at time $t, g^{i t}$ denotes life satisfaction, $c^{i t}=z^{i t}-T^{i t}$ real net household income, and $l^{i t}$ hours worked. Furthermore, $x_{j}^{i t}$ are control variables, $\zeta^{t}$ are time-fixed effects, $\zeta^{i}$ individual-fixed effects, and $v^{i t}$ is the error term.

Notice that I assume that the functional form of well-being is, apart from a constant, identical across persons and stable over time. While this is not ideal - preferably I would allow the well-being function to be fully heterogeneous across individuals and years - it is impossible to avoid these assumptions given the limited amount of data points per individual. Moreover, well-being is assumed to be logarithmic in income and quadratic in hours worked. The latter assumptions on functional form are relaxed when I test the robustness of my results by applying semi-parametric regression techniques. Finally, and crucially, I assume that observed changes in income and working hours are exogenous to life satisfaction and thus rule out the relevance of both omitted variables and reversed causality. Naturally, this assumption is a source of concern in the absence of 

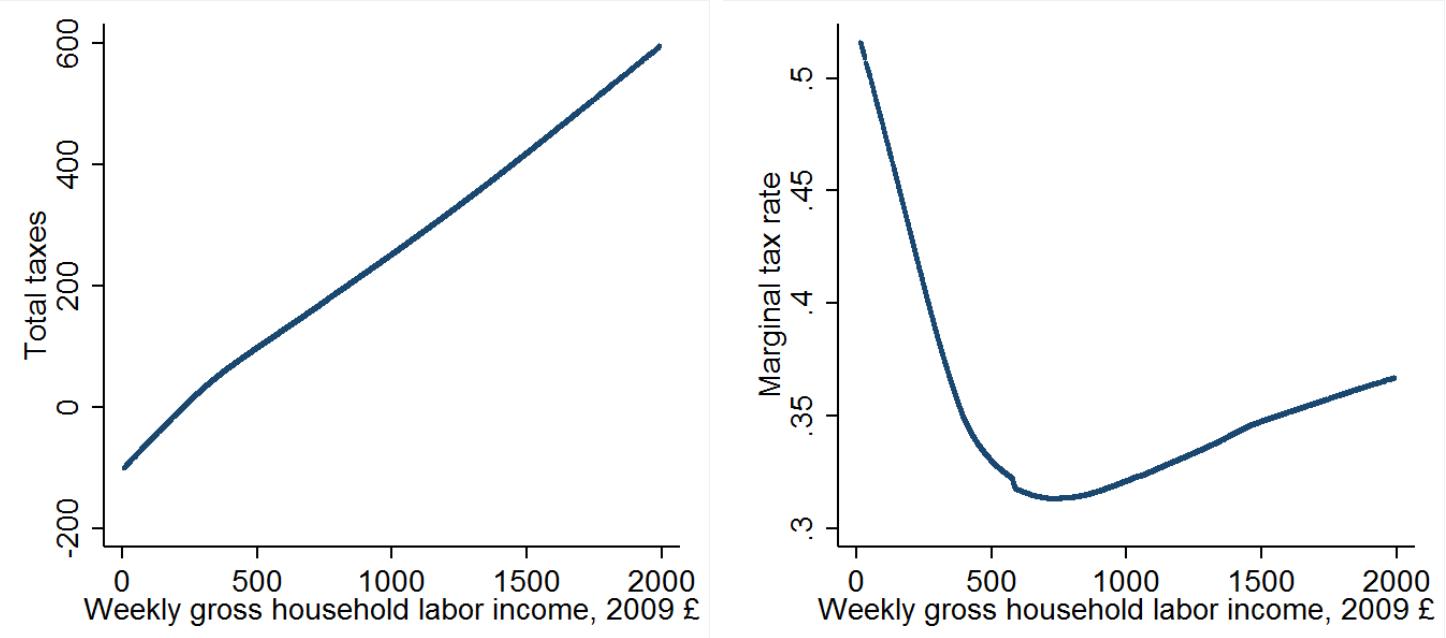

Figure 4: Empirical total tax and marginal tax schedules

a proper quasi-experimental design. As discussed above, I try to address these concerns by restricting my sample to exclude the most obvious cases of endogeneity.

Taking derivatives of eq. (i) implies I can write the well-being based marginal rate of substitution of leisure for consumption as:

$$
\frac{-g_{l}^{i t}}{g_{l}^{i t}}=\left(\frac{-a_{1}}{a_{0}}+2 \frac{-a_{2}}{a_{0}} l^{i t}\right) c^{i t} .
$$

Hence, the estimation of eq. (i) provides the first ingredient of the extent to which people work too much. The second set of ingredients include wages and marginal tax rates. The wage rate $w^{i t}$ is calculated by dividing the individual's gross labor income by the number of hours worked. The marginal tax rate is obtained by the following procedure. First, total taxes are determined by taking the difference between households' gross and net labor income, including income-dependent transfers and subsidies. Next, the resulting variable is smoothed over gross income and a numerical derivative is taken. This numerical derivative is taken to be the marginal tax rate. It is thus implicitly assumed that effective labor taxes are a function of household labor income. While this assumption is less accurate for moderate-to-high income workers as the income tax system in the United Kingdom is individual based, it is more accurate for low-income workers as eligibility for transfers and benefits generally depend on household income (see, e.g., Brewer, Saez, and Shephard (2010)). ${ }^{17}$ Figure 4 depicts the total tax schedule (first panel) and the marginal tax schedule (second panel). Due to the phasing out of transfers and benefits, marginal taxes are relatively high for low-income levels.

This provides all the ingredients needed to calculate $\omega^{i t}$. Notice that in the definition

\footnotetext{
${ }^{17} \mathrm{I}$ also performed the exact same analysis while focussing on individual taxation. As expected, this resulted in much lower marginal tax rates at the bottom, since the phasing out of household-income dependent transfers and benefits are not taken into account. However, the general results of this section remain entirely intact.
} 
of the total wedge on labor income - given by the left-hand side of eq. (14) $-\omega^{i t}$ is multiplied by the welfare weight $a^{i t}=\gamma^{i} g_{c}^{i t} / \lambda$. To determine the total wedge, I assume that government is utilitarian, such that $\gamma^{i}=\gamma$ for all $i$. More redistributive preferences would cause $a^{i t}$ to be more decreasing with income, increasing the corrective argument for low-income workers at the cost of high-income workers. I moreover assume that government is on average indifferent between marginal resources in the hands of the public sector or the private sector, such that $\lambda$ equals the simple average of the social marginal well-being of income: $\lambda=\sum_{i, t} \gamma g_{c}^{i t} / N$, where $N$ is the total number of individuals. ${ }^{18}$

\subsection{Evidence on suboptimal behavior and the wedge on labor}

The results of estimating eq. (i) are given in Table 1. The first column shows results for the entire sample, while the second and third columns show the results of separate regressions for male and female respondents. For all regressions the coefficient on income is significant and around 0.18 , which is to say that a percentage increase of net household income is associated with an increase in life satisfaction of (approximately) a hundredth of 0.18 point. While this effect seems rather small, it is in fact comparable to earlier results in the literature. As can be seen from the first column, the coefficient on the linear working hours term is positive while the coefficient on the quadratic term is negative. This is suggestive of an inverted-' $U$ ' shaped relationship between life satisfaction and hours worked. It is easily verified that the top of this parabola is around 30 hours of work, after which every additional working hour is associated with decreased life satisfaction. These findings are confirmed when the sample is restricted to male respondents, but loses its statistical significance when the sample is restricted to female respondents. The insignificant result for female respondents might well be due to the small sample size, especially considering the fact that, in the remaining sample, the average number of sampled years per person is less than three.

By substituting the estimated coefficients of Table 1 into eq. (16), I obtain a measure of individuals' marginal rates of substitution of leisure for consumption. Further substituting this, along with data on wages and marginal tax rates, into eq. (4) yields a measure of $\omega^{i t}$ for every person and year in the sample. If positive, the person works too much from a well-being point of view; if negative, the person works too little. Figure 5 shows how values for $\omega^{i t}$ are distributed for both the full and the male sample. While values are concentrated around zero, there remains significant variation across the population. Since (corrective) taxation is conditioned on labor income, it is most informative to show how $\omega^{i t}$ varies over gross household labor income. The smoothed values of $\omega^{i t}$ are depicted in the first panel of Figure 6. This graph illustrates that up to a weekly gross

\footnotetext{
${ }^{18}$ As show in eq. (12), this condition is necessarily true in the tax optimum. Outside the optimum, however, it is generally unclear whether public resources are on average valued more or less than private resources (cf. Jacobs, 2013)
} 
Table 1: Estimation results for eq. (i)

\begin{tabular}{|c|c|c|c|}
\hline & All & Male & Female \\
\hline $\log$ income & $\begin{array}{c}0.182^{* * *} \\
(0.0332)\end{array}$ & $\begin{array}{c}0.146^{* * *} \\
(0.0392)\end{array}$ & $\begin{array}{c}0.217^{* * *} \\
(0.0641)\end{array}$ \\
\hline hours & $\begin{array}{c}0.00762^{* *} \\
(0.00346)\end{array}$ & $\begin{array}{c}0.00953^{* *} \\
(0.00384)\end{array}$ & $\begin{array}{c}0.00137 \\
(0.00790)\end{array}$ \\
\hline hours squared & $\begin{array}{c}-0.000126 * * * \\
(4.62 \mathrm{e}-05)\end{array}$ & $\begin{array}{c}-0.000158 * * * \\
(5.05 \mathrm{e}-05)\end{array}$ & $\begin{array}{c}-7.72 \mathrm{e}-06 \\
(0.000111)\end{array}$ \\
\hline Observations & 13,529 & 9,908 & 3,621 \\
\hline R-squared (within) & 0.033 & 0.031 & 0.065 \\
\hline Number of individuals & 4,194 & 2,942 & 1,252 \\
\hline
\end{tabular}

Dependent variable: life satisfaction. All regressions include age dummies, subjective health dummies (on a scale from 1 to 5), year dummies, and marital status dummies, as well as person-fixed effects.

labor income of around $£ 850$, individuals tend to supply too little labor. Conversely, individuals that earn more than that tend to supply too much labor from a well-being point of view. In line with what stated preferences suggest in Figure 1, the degree to which people work too much is generally increasing with gross labor income.

I can now readily determine the total wedge on labor earnings as given by the lefthand side of eq. (14). For this, I substitute for the empirical measure of $\omega^{i t}$, the marginal welfare weights $a^{i t}$, and the empirical marginal tax schedule. The smoothed values of the total wedge are illustrated by the blue line in the second panel of Figure 6 . The red line shows the tax wedge, $\frac{T_{z}^{i t}}{1-T_{z}^{i t}}$, which is traditionally taken as the wedge on labor earnings. As low-income workers work too little, an increase in their labor earnings not only leads to higher tax revenue but also to well-being gains. The total wedge on labor earnings therefore exceeds the tax wedge alone. For high-income workers the opposite holds: an increase in their labor earnings raise tax revenue but reduces their well-being because they already work too much. For this reason, the total wedge is smaller than the tax wedge. As the welfare weights are rapidly decreasing with income, the difference between the total wedge and the tax wedge is more pronounced for low-income workers than for high-income workers.

Figure 7 illustrates the extent to which people work too much (first panel) and the total wedge on labor earnings (second panel) if the analysis is restricted to male workers only. The previous results more or less carry over to a male-only sample. This time, however, only people with a very low income work too little from a well-being perspective, whereas the rest works far too much. As a result, the total wedge on labor earnings for median-to-high income workers is much lower than the tax wedge alone. In fact, the total 

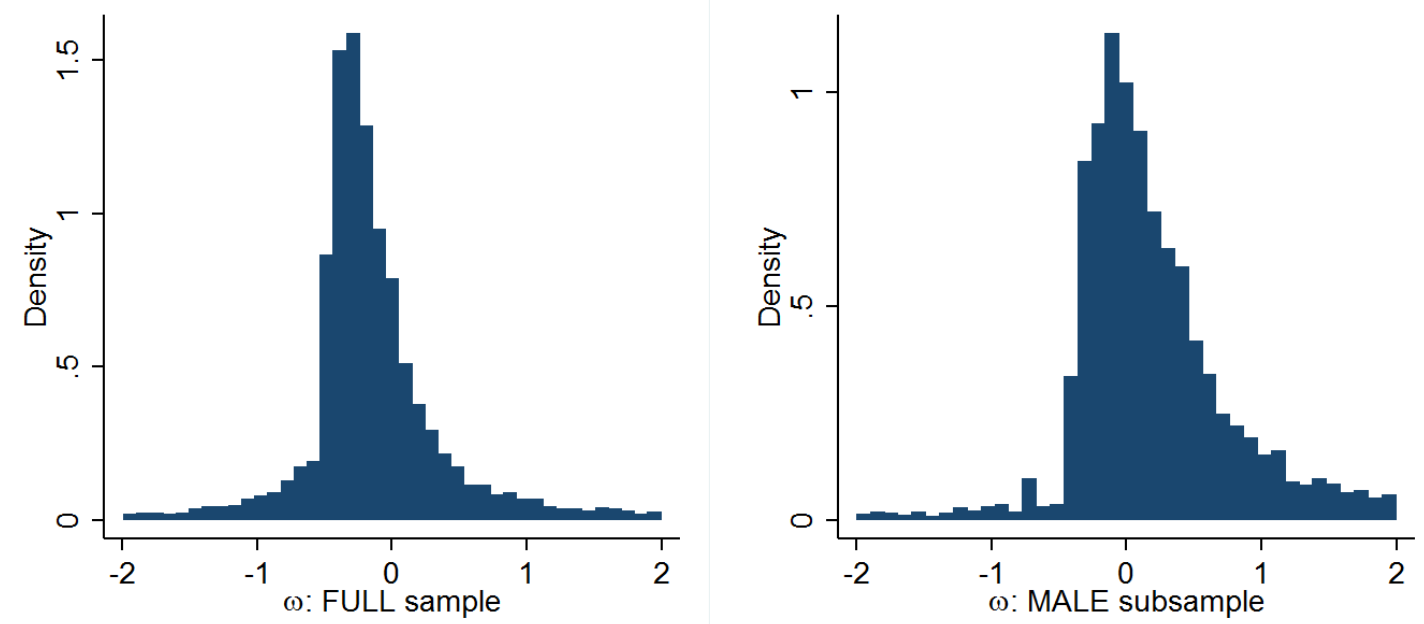

Figure 5: Histogram of $\omega$, full and male sample
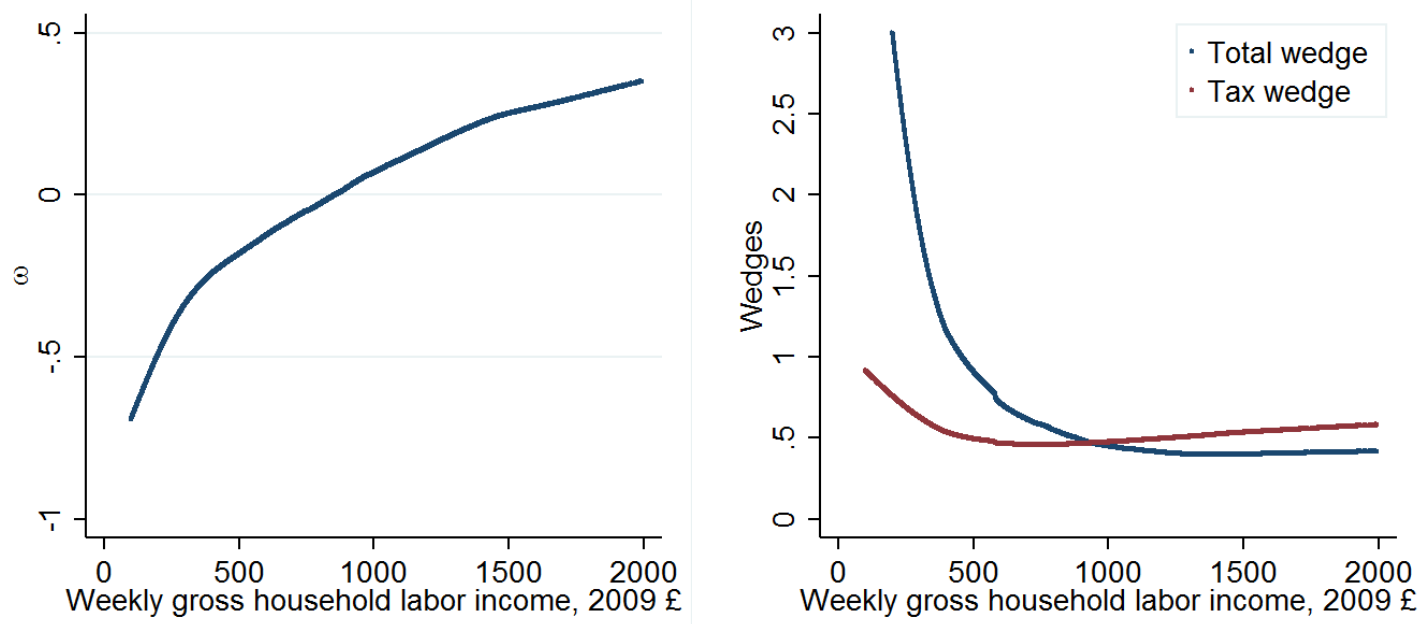

Figure 6: $\omega$ and wedges, full sample
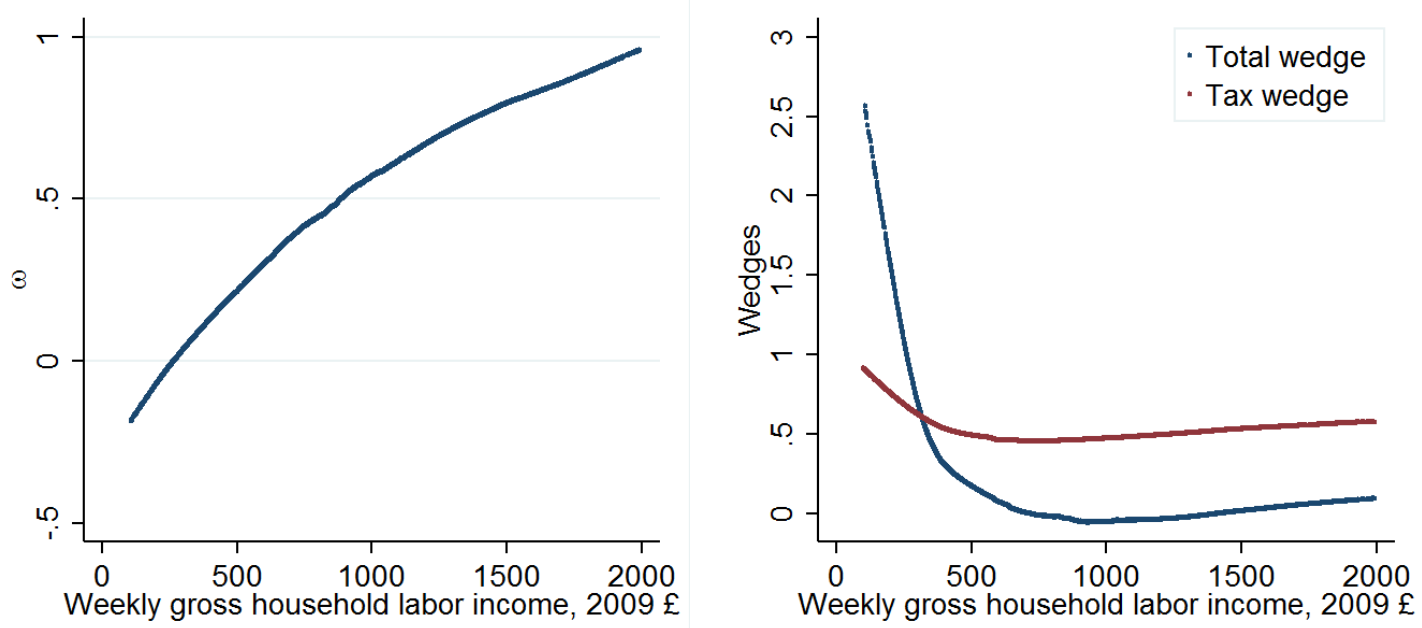

Figure 7: $\omega$ and wedges, male subsample 
wedge hovers around zero for a significant range of the income distribution. For these income groups, the tax revenue gain associated with an increase in labor earnings would be completely offset by well-being losses. As a result, since the marginal dead-weight loss of taxation is proportional to the wedge on labor effort, the net distortions associated with higher marginal taxes would be negligible for these income groups.

\subsection{Robustness}

Potentially crucial to the above analysis is the specific functional form of the well-being function. In the previous section I simply assumed that well-being was additive in its arguments, logarithmic in income, and quadratic in working hours. In this section, I retain the assumption of additivity but attempt to determine the sensitivity of the results to the way in which income and working hours enter the well-being function. As theoretically very little can be said on the functional form of well-being, I apply semi-parametric regression techniques that allow for a large degree of flexibility with respect to the specific functional form.

\subsubsection{Income}

I first try to get a better understanding of the relationship between life satisfaction and income. For this, I estimate the following partially linear model:

$$
g^{i t}=\phi^{c}\left(c^{i t}\right)+a_{1} l^{i t}+a_{2}\left(l^{i t}\right)^{2}+\sum_{j} b_{j} x_{j}^{i t}+\zeta^{t}+\zeta^{i}+u^{i t}
$$

where all variables are the same as before, and $\phi^{c}(\cdot)$ is an unspecified function. The equation is estimated using the algorithm developed by Lokshin (2006), who applies a locally weighted scatterplot smoothing (lowess) estimator to determine $\phi^{c}(\cdot)$. The resulting values of $\phi^{c}\left(c^{i t}\right)$, for different levels of $c^{i t}$, are shown in the first panel of Figure 8. The blue line illustrates the estimated values for the full sample, and the green (red) line illustrates the estimated values if the sample is restricted to males (females) only. These results are suggestive of a concave relationship between well-being and income, although seemingly linear for females.

However, even if the relationship between well-being and income is concave, it does not follow that a logarithmic specification is the correct one. For example, Layard, Mayraz, and Nickell (2008) find in a similar setup that the relationship between well-being and income is best captured by a function that is slightly more concave than a logarithmic function. To determine whether the results of Section 2 are sensitive to the degree of 

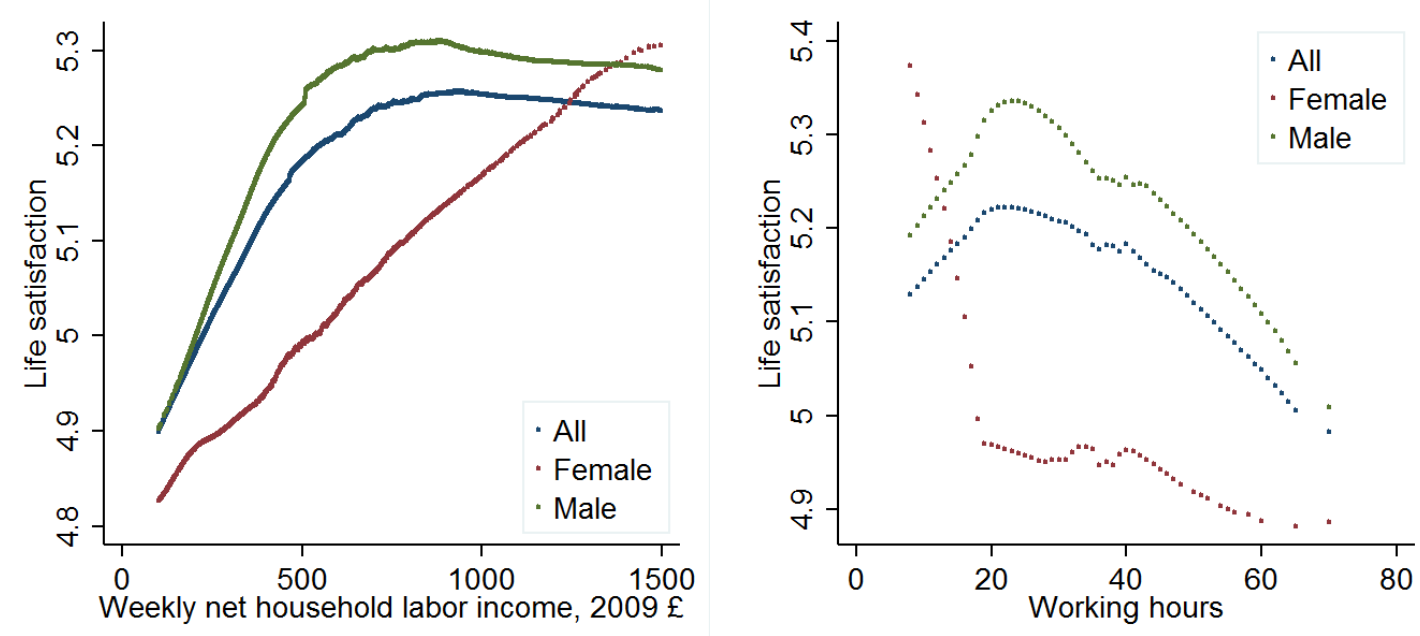

Figure 8: Non-parametric estimation results for income and working hours

concavity, I estimate the following equation:

$$
g^{i t}=a_{0}\left(\frac{\left(c^{i t}\right)^{1-\rho}-1}{1-\rho}\right)+a_{1} l^{i t}+a_{2}\left(l^{i t}\right)^{2}+\sum_{j} b_{j} x_{j}^{i t}+\zeta^{t}+\zeta^{i}+u^{i t},
$$

for various values of $\rho$, allowing for varying degrees of concavity. On the basis of these estimations I derive $\omega^{i t}$ and the total wedge. Results for $\rho=\{0.1,0.5,1.5\}$ are depicted in Figure $9 .{ }^{19}$ As can be seen, the results remain in line with what I found earlier. Lowincome workers work too little, while high-income workers work too much. Consequently, the total wedge on labor for low-income workers exceeds the tax wedge, whereas the total wedge for high-income workers is smaller than the tax wedge. Only in the case of a very low degree of concavity $(\rho=0.1)$, even the moderately poor seem to be working too much.

\subsubsection{Working hours}

Next, I further determine the results' sensitivity to the way working hours enter the well-being function. I estimate the following equation:

$$
g^{i t}=a_{0} \ln c^{i t}+\phi^{l}\left(l^{i t}\right)+\sum_{j} b_{j} x_{j}^{i t}+\zeta^{t}+\zeta^{i}+u^{i t}
$$

with $\phi^{l}(\cdot)$ an unspecified function to be estimated non-parametrically. The resulting estimated values for $\phi^{l}\left(l^{i t}\right)$, separately for the full sample (blue), and the male (green) and female (red) subsamples, are shown in the second panel of Figure 8. For both the full sample and the male subsample, the relationship between life satisfaction and

\footnotetext{
${ }^{19}$ To save on space, I only depict the results for these three values of $\rho$. The results remain broadly the same for any other positive value of $\rho$ that I tried.
} 

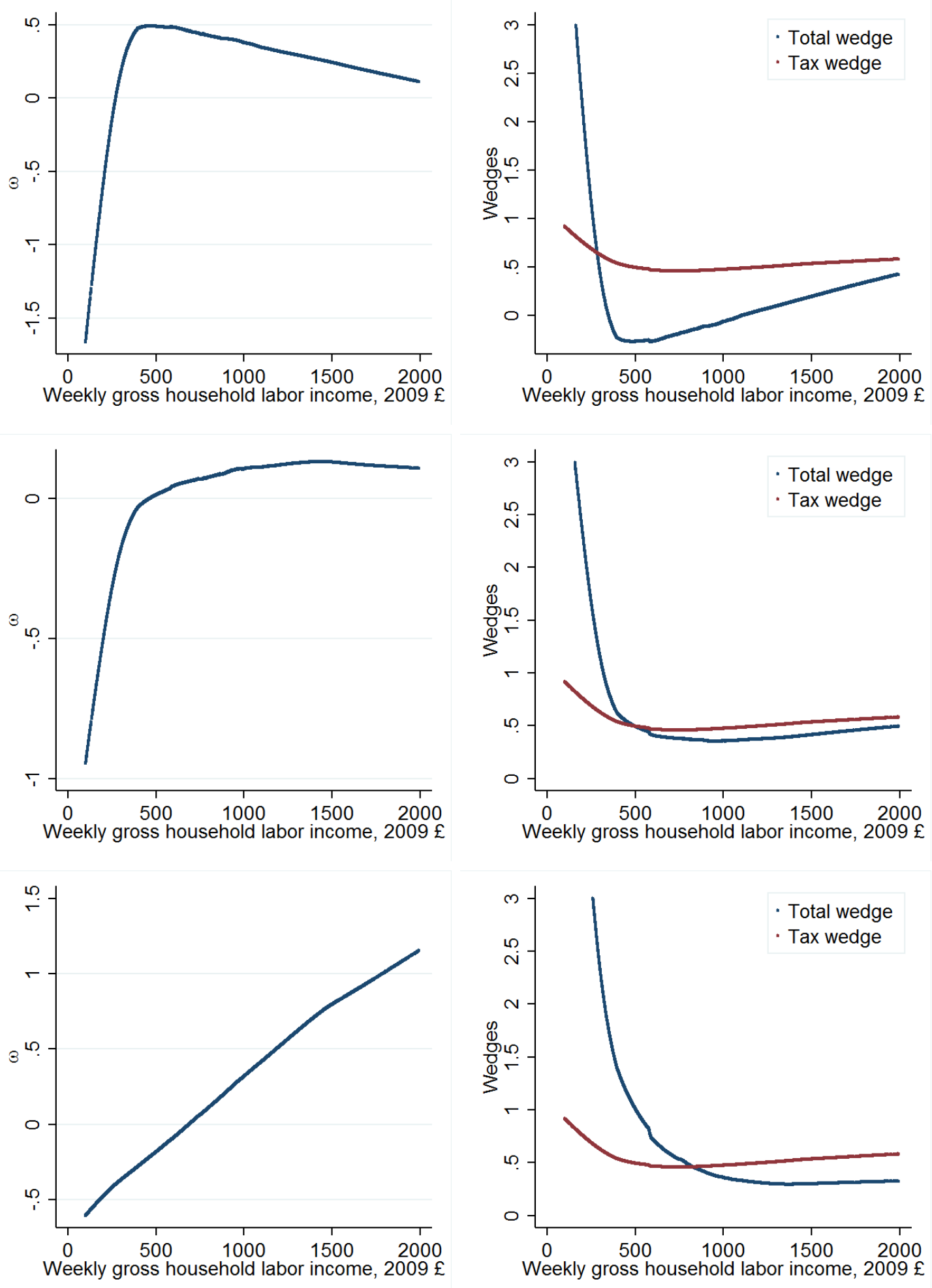

Figure 9: $\omega$ and wedges based on eq. (iii), for $\rho=0.1$ (upper panels), $\rho=0.5$ (middle panels), and $\rho=1.5$ (lower panels) 

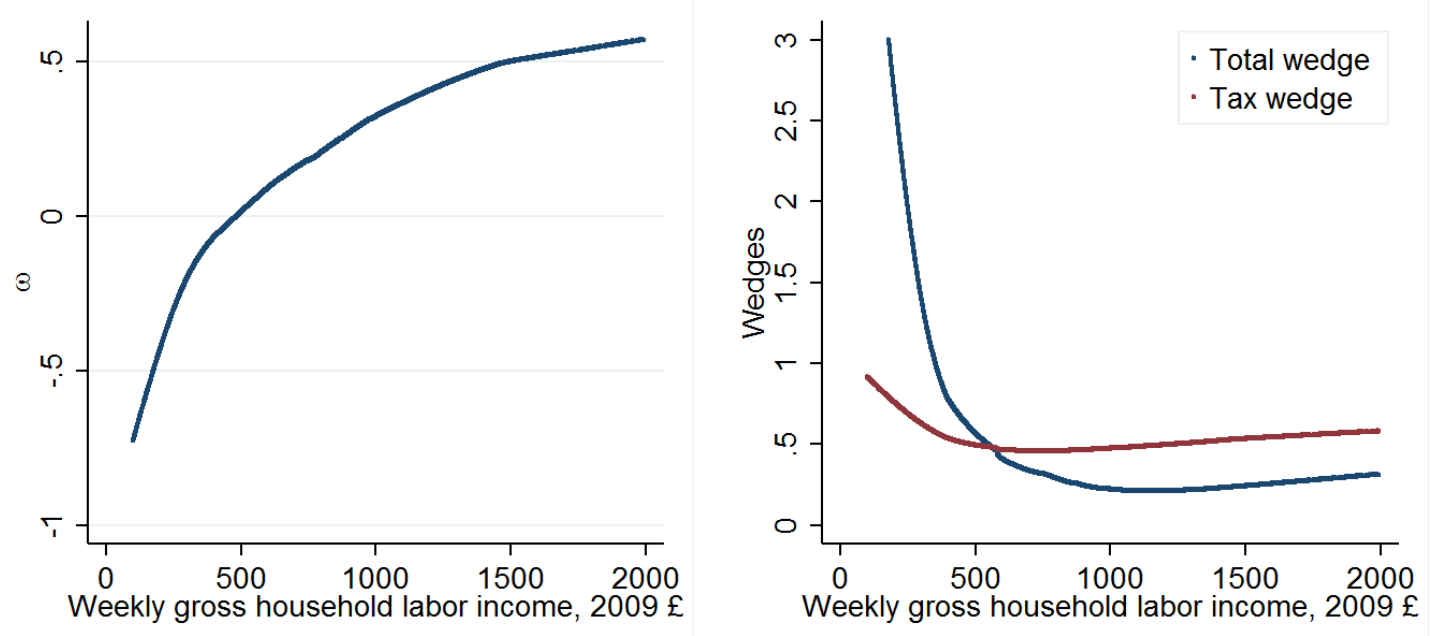

Figure 10: $\omega$ and wedges based on eq. (iv)

working hours appears to resemble an inverted ' $U$ '. This corroborates the results of the parametric regressions in which the quadratic specification of working hours indicated a similar relationship. For female respondents no clear relationship is visible, which also corroborates earlier findings.

Even if the semi-parametric estimation indicates an inverted-'U' shaped pattern, this does not imply that the quadratic specification is correct. To test the robustness of my results, I therefore determine the marginal well-being of labor hours, $g_{l}^{i t}$, by numerically taking the derivative of the estimated values of $\phi^{l}\left(l^{i t}\right)$. Together with the estimated value of $g_{c}^{i t}$ from eq. (iv), this allows me to determine values for $\omega^{i t}$ and total wedges. These values are illustrated in Figure 10. As before, low-income workers appear to be working too little, whereas high-income workers are working too much. Hence, previous results appear insensitive to the way in which income and working hours enter the well-being function.

\subsection{Discussion of the empirical results}

The standard approach to applied optimal taxation is to determine the optimal wedge on labor earnings and compare this to the actually observed tax wedge. Policy recommendations are distilled from the difference between the optimal wedge and the actual tax wedge. However, as shown by eq. (14), the optimal wedge on labor earnings should in fact be compared to the actual total wedge, not just the actual tax wedge. My empirical findings suggest that standard applied studies of optimal taxation might underestimate the wedge for low-income workers and overestimate the wedge for high-income workers. As a result, their recommendations understate the required tax decrease for low-income workers, as well as the required tax increase for high-income workers. 
As a concrete example, consider the tax reforms that have recently been suggested for the United Kingdom by Brewer, Saez, and Shephard (2010) and Blundell and Shephard (2012). Both studies call for a reduction of marginal tax rates for low-to-moderate earners. They conclude that current marginal tax rates for low-income workers are such that the distortions on intensive labor supply are too large to be justified by redistributive gains. My empirical findings suggest that these recommendations hold a fortiori. Encouraging low-income workers to work more not only raises tax revenue but also improves their own well-being. The more government cares about low-income workers, the more important the latter corrective argument is.

It is useful, however, to also take stock of the limitations of the empirical analysis. Even if it correctly identifies low-income workers as working too little, the analysis has very little to say about the underlying causes for individuals' suboptimal behavior. This implies that we cannot tell whether low-income workers that work too little will be responsive to a tax cut. The analysis of Section 1, however, showed that the corrective argument for taxation only holds if misoptimizers are responsive to taxation. One reason why some low-income workers might be working too little is because they might be facing demand restrictions if wages are above their market-clearing levels - e.g., due to minimum wages, union wages, efficiency wages, or some other form of downward wage rigidity. ${ }^{20,21}$ In that case, workers' labor supply might in part be determined by firms, rather than by workers themselves. This would make workers who work too little less responsive to taxes, reducing the well-being gains of any tax cut. Other instruments, such as firm-side tax cuts, might then be more effective in raising the well-being of low-income workers.

To obtain some indication of whether demand restrictions play an important role among people who supply too little labor, one could revisit the BHPS question on whether individuals are satisfied with their working hours. If individuals with low levels of $\omega^{i t}$ would actually be maximizing their well-being but be constrained by firms in increasing their working hours, one would expect most of them to indicate they prefer working more hours. The distribution of answers for different levels of $\omega^{i t}$ are given in Table 2. The percentage of respondents that wants to work more hours is indeed increasing with $\omega^{i t}$. However, even for very low values of $\omega^{i t}$, many people still state that they prefer working the same number of hours. This suggests that demand restrictions might not be the most important explanation for my findings. I consider determining the exact underlying reasons for suboptimal labor market behavior as an important avenue for further research.

\footnotetext{
${ }^{20}$ In this light, it is worthwhile to reiterate the fact that the latest observations in the dataset stem from 2008, which is before the recent crisis caused involuntary unemployment rates to soar.

${ }^{21}$ Naturally, such considerations also have important consequences for traditional studies of optimal taxation. However, within the field of public economics, the possible existence of labor demand restrictions have largely been neglected. Recent exceptions are Landais, Michaillat, and Saez (2013) and Gerritsen (2013).
} 
Table 2: Satisfaction with labor hours and $\omega^{i t}$

\begin{tabular}{lcccc}
\hline$\omega^{i t} \in$ & $\left(-\infty,-\frac{1}{2}\right)$ & {$\left[-\frac{1}{2}, 0\right)$} & {$\left[0, \frac{1}{2}\right)$} & {$\left[\frac{1}{2}, \infty\right)$} \\
\hline & & & & \\
Prefer fewer hours (\%) & 21.8 & 40.2 & 43.0 & 52.6 \\
Prefer more hours (\%) & 14.0 & 3.5 & 3.2 & 1.7 \\
Same number of hours (\%) & 64.1 & 56.3 & 53.7 & 45.7 \\
& & & & \\
Observations & 1,575 & 7,885 & 2,386 & 1,617 \\
\hline
\end{tabular}

\section{Concluding remarks}

To the best of my knowledge, this is the first study to integrate the large empirical literature on the determinants of subjective well-being with the theoretically rigorous study of public finance. It is based on the notion that individuals do not necessarily maximize their own well-being. I find that the resulting optimal wedge on labor earnings is virtually identical to the one derived under conventional studies. However, the wedge itself consists of the well-being consequences of drawing an individual farther from or closer to its well-being bliss point, as well as the standard tax wedge. Optimal marginal tax rates should be higher for workers that work too much from a well-being perspective, and lower for workers that work too little.

Using data on life satisfaction as a measure of a person's well-being, I estimate the effect of income and working hours on well-being for a large panel of British individuals. The results suggest that low-income workers tend to work less than optimal from a wellbeing point of view. Higher-income workers, on the other hand, tend to work too much. Moreover, this finding is robust to varying assumptions on the functional form of wellbeing. Compared to standard derivations of optimal tax rates, these results endorse lower marginal tax rates at the lower end of the income distribution, and higher marginal tax rates at the higher end of the income distribution. Recommendations of recent studies, calling for a reduction of marginal tax rates for low earners in the United Kingdom, therefore hold a fortiori.

Perhaps more important, this study shows that it is possible to combine the rigor and emphasis on incentives that is typical for the theory of optimal taxation, with an alternative measurement of well-being. My hope is that this might contribute to (i) more attention to economic incentives and optimal policy within applied studies of the determinants of subjective well-being, and (ii) a less dogmatic approach to well-being within public finance. 


\section{Appendix}

\section{Elasticities in the canonical model of labor supply}

This Appendix characterizes elasticities in terms of the deeper characteristics of the canonical model of labor supply. In this model, individuals decide on their labor income by maximizing their (decision) utility - which might differ from his actual well-being (or experienced utility). Utility of individual $i$ is assumed to be increasing in consumption and decreasing in labor effort. As the paper abstracts from income effect, I can write utility as:

$$
u^{i} \equiv z^{i}-T\left(z^{i}, \kappa\right)-v\left(z^{i} / w^{i}\right), \quad v_{l}^{i}, v_{l l}^{i}>0
$$

Utility maximization implies:

$$
v_{l}^{i}\left(z^{i} / w^{i}\right)=\left(1-T_{z}^{i}\left(z^{i}, \kappa\right)\right) w^{i}
$$

Suppressing function arguments, the second-order condition is given by:

$$
-\frac{l^{i} v_{l l}^{i}}{v_{l}^{i}}-\frac{T_{z z}^{i} z^{i}}{1-T_{z}^{i}}<0
$$

which, by convexity of $v^{i}$, holds as long as the tax schedule is not too concave at $z^{i}$. A reform's effect on individual $i$ 's taxable income is obtained by taking the total derivative of eq. (18). Rearranging yields the following (compensated and uncompensated) net-of-tax rate elasticity of taxable income:

$$
e^{i} \equiv-\frac{\mathrm{d} z^{i}}{\tau_{z}\left(z^{i}\right) \mathrm{d} \kappa} \frac{1-T_{z}^{i}}{z^{i}}=\left(\frac{l^{i} v_{l l}^{i}}{v_{l}^{i}}+\frac{T_{z z}^{i} z^{i}}{1-T_{z}^{i}}\right)^{-1}>0
$$

where the inequality sign follows from the second-order condition. The second deriviative of the tax schedule enters the elasticity because any change in taxable income induces a second-round change in marginal taxes as long as $T_{z z}^{i} \neq 0$ - also see footnote 9 in the main text.

\section{References}

Allcott, Hunt, Sendhil Mullainathan, and Dmitry Taubinsky. 2014. "Energy policy with externalities and internalities." Journal of Public Economics 112:72-88.

Atkinson, Anthony B and Joseph E Stiglitz. 1976. "The design of tax structure: Direct versus indirect taxation." Journal of Public Economics 6 (1-2):55-75. 
Bernheim, B Douglas and Antonio Rangel. 2007. "Behavioral public economics: Welfare and policy analysis with non-standard decision makers." In Behavioral Economics and its Applications, edited by Peter Diamond and Hannu Vartiainen. New Jersey: Princeton University Press, 7-77.

Blomquist, Sören and Luca Micheletto. 2006. "Optimal redistributive taxation when government's and agents' preferences differ." Journal of Public Economics 90 (6):12151233.

Blundell, Richard and Andrew Shephard. 2012. "Employment, hours of work and the optimal taxation of low-income families." Review of Economic Studies 79 (2):481-510.

Booth, Alison L and Jan C Van Ours. 2008. "Job satisfaction and family happiness: The part-time work puzzle." The Economic Journal 118 (526):F77-F99.

Brewer, Mike, Emmanuel Saez, and Andrew Shephard. 2010. "Means-testing and tax rates on earnings." In Dimensions of Tax Design: The Mirrlees Review, edited by James Mirrlees, Stuart Adam, Timothy Besley, Richard Blundell, Stephen Bond, Robert Chote, Malcolm Gammie, Paul Johnson, Gareth Myles, and James Poterba. Oxford: Oxford University Press, 90-173.

Camerer, Colin, George Loewenstein, and Drazen Prelec. 2005. "Neuroeconomics: How neuroscience can inform economics." Journal of Economic Literature 43 (1):9-64.

Chetty, Raj. 2009. "Sufficient statistics for welfare analysis: a bridge between structural and reduced-form methods." Annual Review of Economics 1 (2):31-52.

_ 2015. "Behavioral economics and public policy: A pragmatic perspective." American Economic Review Papers and Proceedings forthcoming.

Chetty, Raj, John N Friedman, Søren Leth-Petersen, Torben Heien Nielsen, and Tore Olsen. 2014. "Active vs. passive decisions and crowd-out in retirement savings accounts: Evidence from Denmark." The Quarterly Journal of Economics 129 (3):1141-1219.

Chetty, Raj, Adam Looney, and Kory Kroft. 2009. "Salience and taxation: Theory and evidence." American Economic Review 99 (4):1145-1177.

Christiansen, Vidar. 1981. "Evaluation of public projects under optimal taxation." The Review of Economic Studies 48 (3):447-457.

- 1984. "Which commodity taxes should supplement the income tax?" Journal of Public Economics 24 (2):195-220. 
Clark, Andrew E., Paul Frijters, and Michael A. Shields. 2008. "Relative income, happiness, and utility: An explanation for the Easterlin paradox and other puzzles." Journal of Economic Literature 46 (1):95-144.

Diamond, Peter A. 1975. "A many-person Ramsey tax rule." Journal of Public Economics $4(4): 335-342$.

Diamond, Peter A. 1998. "Optimal income taxation: an example with a U-shaped pattern of optimal marginal tax rates." The American Economic Review 88 (1):83-95.

Farhi, Emmanuel and Xavier Gabaix. 2015. "Optimal taxation with behavioral agents." Mimeo.

Gerritsen, Aart. 2013. "Equity and efficiency in rationed labor markets." Mimeo. 2015. "Optimal nonlinear taxation: the dual approach." Mimeo.

Gul, Faruk and Wolfgang Pesendorfer. 2008. "The case for mindless economics." In The Foundations of Positive and Normative Economics: A Handbook, edited by Andrew Caplin and Andrew Shotter. New York: Oxford University Press, 3-42.

Hausman, Daniel M. 2011. Preference, Value, Choice, and Welfare. New York: Cambridge University Press.

Jacobs, Bas. 2013. "The marginal cost of public funds is one at the optimal tax system." Mimeo.

Jacobs, Bas and Ruud A. de Mooij. 2015. "Pigou meets Mirrlees: On the irrelevance of tax distortions for the second-best Pigouvian tax." Journal of Environmental Economics and Management forthcoming.

Jacquet, Laurence and Etienne Lehmann. 2015. "Optimal income taxation when skills and behavioral elasticities are heterogeneous." Mimeo.

Jacquet, Laurence, Etienne Lehmann, and Bruno Van der Linden. 2013. "Optimal redistributive taxation with both extensive and intensive responses." Journal of Economic Theory 148 (5):1770-1805.

Kahneman, Daniel and Richard H Thaler. 2006. "Anomalies: Utility maximization and experienced utility." The Journal of Economic Perspectives 20 (1):221-234.

Kahneman, Daniel, Peter P. Wakker, and Rakesh Sarin. 1997. "Back to Bentham? Explorations of experienced utility." The Quarterly Journal of Economics 112 (2):375-405.

Kanbur, Ravi, Jukka Pirttilä, and Matti Tuomala. 2006. "Non-welfarist optimal taxation and behavioural public economics." Journal of Economic Surveys 20 (5):849-868. 
Knabe, Andreas and Steffen Rätzel. 2010. "Income, happiness, and the disutility of labour." Economics Letters 107 (1):77-79.

Köszegi, Botond and Matthew Rabin. 2008. "Choices, situations, and happiness." Journal of Public Economics 92 (8-9):1821-1832.

Landais, Camille, Pascal Michaillat, and Emmanuel Saez. 2013. "Optimal unemployment insurance over the business cycle." National Bureau of Economic Research Working Paper No. 16526.

Layard, Richard. 2011. Happiness: Lessons from a new science. Penguin UK.

Layard, Richard, Guy Mayraz, and Stephen Nickell. 2008. "The marginal utility of income." Journal of Public Economics 92 (8-9):1846-1857.

Liebman, Jeffrey B and Richard J Zeckhauser. 2004. "Schmeduling." Mimeo.

Lockwood, Benjamin B. 2015. "Present Bias and the optimal taxation of low incomes." Mimeo.

Loewenstein, George, Ted O'Donoghue, and Matthew Rabin. 2003. "Projection bias in predicting future utility." The Quarterly Journal of Economics 118 (4):1209-1248.

Lokshin, Michael. 2006. "Semi-parametric difference-based estimation of partial linear regression models." Stata Journal 6 (3):377-383.

Mill, John Stuart. 1863. Utilitarianism. London: Parker, Son, and Bourn, West Strand.

Mirrlees, James A. 1971. "An exploration in the theory of optimum income taxation." Review of Economic Studies 38 (2):175-208.

. 1976. "Optimal tax theory: A synthesis." Journal of Public Economics 6 (4):327358.

O'Donoghue, Ted and Matthew Rabin. 2006. "Optimal sin taxes." Journal of Public Economics 90 (10):1825-1849.

Piketty, Thomas and Emmanuel Saez. 2013. "Optimal labor income taxation." In Handbook of Public Economics, vol. 5, edited by Alan J Auerbach, Raj Chetty, Martin Feldstein, and Emmanuel Saez. Amsterdam: Elsevier, 391-474.

Pouwels, Babette, Jacques Siegers, and Jan Dirk Vlasblom. 2008. "Income, working hours, and happiness." Economics Letters 99 (1):72-74.

Rabin, Matthew. 1998. "Psychology and economics." Journal of Economic Literature $36(1): 11-46$. 
Saez, Emmanuel. 2001. "Using elasticities to derive optimal income tax rates." Review of Economic Studies 68 (1):205-229.

Sandmo, Agnar. 1975. "Optimal taxation in the presence of externalities." The Swedish Journal of Economics 77 (1):86-98.

Sanfey, Alan G, James K Rilling, Jessica A Aronson, Leigh E Nystrom, and Jonathan D Cohen. 2003. "The neural basis of economic decision-making in the ultimatum game." Science 300 (5626):1755-1758.

Seade, Jesus. 1980. "Optimal non-linear policies for non-utilitarian motives." In Income Distribution: The Limits to Redistribution, edited by David A. Collard, Richard Lecomber, and Martin Slater. Bristol: Scientechnica.

Stern, Nicholas. 1982. "Optimum taxation with errors in administration." Journal of Public Economics 17 (2):181-211.

Stiglitz, Joseph E. 1982. "Self-selection and Pareto efficient taxation." Journal of Public Economics 17 (2):213-240. 